\title{
The nature of ligand efficiency
}

\author{
Peter W. Kenny*
}

Berwick-on-Sea, North Coast Road, Blanchisseuse, Saint George, Trinidad and Tobago

ABSTRACT

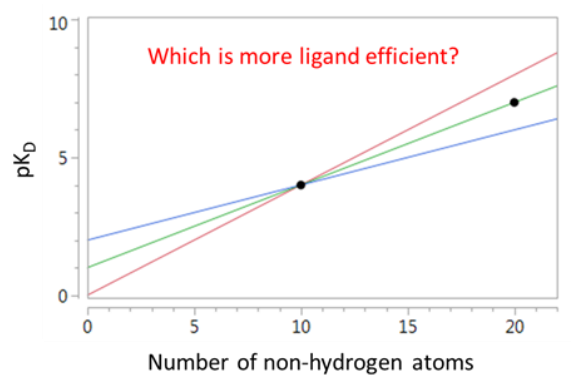

$$
\frac{\Delta p K_{D}}{\Delta N_{n H}} \neq \Delta\left(\frac{p K_{D}}{N_{n H}}\right)
$$

Ligand efficiency is a widely used design parameter in drug discovery. It is calculated by scaling affinity by molecular size and has a nontrivial dependency on the concentration unit used to express affinity that stems from the inability of the logarithm function to take dimensioned arguments. Consequently, perception of efficiency varies with the choice of concentration unit and it is argued that the ligand efficiency metric is not physically meaningful nor should it be considered to be a metric. The dependence of ligand efficiency on the concentration unit can be eliminated by defining efficiency in terms of sensitivity of affinity to molecular size and this is illustrated with reference to fragment-to-lead optimizations. An alternative to ligand efficiency for normalization of affinity with respect to molecular size is presented. Group efficiency and fit quality are also examined in detail from a physicochemical perspective. The importance of examining relationships between affinity and molecular size directly is stressed throughout this study.

Keywords: cheminformatics, drug design, drug discovery, FBDD, FBLD, fragment-based lead discovery, fit quality, group efficiency, hit-to-lead, LE, ligand efficiency, maximal binding affinity, medicinal chemistry, molecular design, molecular interactions, molecular recognition, physical-organic chemistry, property-based design, thermodynamics 


\section{INTRODUCTION}

"I know I could," the VP of discovery responded tartly. "But what do you think you're here for? I could order my own consumables, too, but that's Milo's job. Your job is to lead us in prayers, and from now on you're going to lead us in a prayer for more ligand efficiency in every project. Is that clear? I think more ligand efficiency is something really worth praying for."

Adapted from Joseph Heller, Catch 22

Ligand efficiency (LE) is, in essence, a good concept that is poorly served by a bad metric. It was introduced [1] as "a useful metric for lead selection", has been discussed at length in reviews [2-6] and is routinely tracked in drug discovery projects. There are actually two ligand efficiencies in drug discovery and these can be seen as different manifestations of what might be called molecular size efficiency (MSE). First, the LE concept, sometimes summarized as 'bang for buck', which can be expressed in terms of the sensitivity of affinity to an increase in molecular size. Second, the compound-level LE metric (more accurately, family of metrics) that was introduced [1] with a view to normalizing affinity of compounds with respect to molecular size. While the LE concept has a solid basis, the LE metric cannot be regarded as physically meaningful because perception of efficiency varies with the concentration unit in which affinity is expressed [7,8]. The difficulty stems from the inability of the logarithm function to take a dimensioned [9] argument which means that it is necessary to scale a $K_{D}$ value by an arbitrary concentration unit to enable its logarithm to be calculated.

Drug design is incremental in nature. This reflects a view [10-12] that it is easier to understand and predict differences in chemical behavior between structurally-related compounds than it is to make absolute predictions directly from molecular structure. Drug action is driven by concentration and affinity determines sensitivity of response to this driving force. Drug design is a multi-objective [13] endeavor and some objectives, such as maximization of affinity against the therapeutic target(s) and minimization of affinity against anti-targets, can be defined clearly. Other objectives, such as controllability of exposure are much more difficult to define and this means that drug design is typically indirect. One significant difficulty [14] in drug design is that unbound intracellular concentration $[15,16]$ cannot generally be measured for drugs in vivo. 
Most chemical starting points for design lack the affinity required to function as drugs and optimization typically results in increased lipophilicity, molecular size and molecular complexity [17,18]. This is the essence of lead-likeness [19]. The Rule of 5 (Ro5) [20] highlights excessive molecular size and lipophilicity as primary design risk factors. Risks associated with molecular complexity [18] are more likely to be encountered in the screening phase of a project. Molecular complexity can also be seen inversely as the degree to which a compound is structurally prototypical $[21,22]$ (e.g., minimally substituted) and might also be defined in terms of the molecular shape [23] of a compound or the roughness [24,25] of its molecular surface. Molecular recognition [26] provides much of the conceptual framework for drug design and many medicinal chemists consider molecular interactions [27] when elaborating chemical start points. While a structure-activity relationship (SAR) can point to the importance of individual interactions, the contribution of a protein-ligand contact to affinity is not, in general an experimental observable $[8,28]$.

In property-based design [29,30], risks associated with structural elaboration, such as poor oral absorption, are assessed according to physicochemical criteria. Within this framework, the most efficient optimization paths are those for which the necessary potency gains are accompanied by the smallest increases in perceived risk. One general objective of optimization projects has been stated [31] as "ensuring that any additional molecular weight and lipophilicity also produces an acceptable increase in affinity”. Efficiency can be seen as sensitivity of affinity to increased risk and this is the basis of what might be termed the LE concept. Kuntz et al (K1999) [32] examined the response of maximal affinity to number of non-hydrogen atoms and Hajduk (H2006) [33] noted that "along the path of ideal optimization, an increase of 1 pK $K_{D}$ unit can be expected for every 64 mass units". Saxty et al (S2007) [34] defined group efficiency (GE) for substitutions by scaling the change in affinity resulting from addition of a substituent by the number of non-hydrogen atoms added. The idea of quantifying sensitivity of chemical behavior to changes in molecular structure can be traced to the work of Hammett $[35,36]$ and the activity cliff $[37,38]$ concept can be seen as part of the same general framework.

Compound-level efficiency metrics are typically constructed by either scaling (i.e., divide affinity by risk factor) or offsetting (i.e., subtract risk factor from affinity) [8]. LE was introduced [1] as a metric to normalize affinity with respect to molecular size by scaling the 
standard free energy of binding, $\Delta \mathrm{G}^{\circ}$, by the number, $\mathrm{N}_{\mathrm{nH}}$, of non-hydrogen atoms (the term heavy atoms is also used) in the molecular structure as follows:

$$
\Delta g\left(T, P, C^{\circ}\right)=-\left(\frac{\Delta G^{\circ}}{N_{n H}}\right)
$$

The standard state was not specified when the LE metric was introduced [1] although it appears to be widely believed [3] that $\mathrm{C}^{\circ}$ must be set to $1 \mathrm{M}$ for calculation of LE. The Achilles heel of the LE metric is its nontrivial dependency [7] on $\mathrm{C}^{\circ}$ and, as conventionally [3] defined, LE has a $1 \mathrm{M}$ concentration unit built into it. As noted [39] by Gilson et al, the choice of a particular value of $\mathrm{C}^{\circ}$, such as $1 \mathrm{M}$, to define the standard state is entirely arbitrary and a requirement that $\mathrm{C}^{\circ}$ only take a specific value cannot be accommodated within the framework of thermodynamics. This means that LE cannot be defined objectively in absolute terms for individual compounds because there is no physical basis for favoring a particular value of $\mathrm{C}^{\circ}$ for calculation of LE.

Although a quantity derived by scaling $\Delta \mathrm{G}^{\circ}$ by a risk factor does not have physical significance, offsetting affinity by a risk factor may give a physically meaningful quantity [8]. Provided that ligand ionization is insignificant, ligand lipophilicity efficiency (LLE) [40], which is also known as lipophilic ligand efficiency (LLE) [3] and lipophilic efficiency (LipE) [41], can be interpreted as the ease of transfer of a ligand from 1-octanol to its binding site [8]. Furthermore, some of the limitations of the 1-octanol/water partitioning system become less significant when working within structural series, as is usually the case for lead optimization [42]. While physical interpretability is certainly a desirable feature for a drug design metric, this alone does not guarantee that a metric will be usefully predictive in drug design.

The principal objectives of this study are to provide an in-depth analysis of LE (and its variants) and to highlight ways in which consideration of LE as a concept might address the serious deficiencies of the compound-level metric. LE is discussed in terms of molecular interactions and binding thermodynamics and some of this discussion is likely to be generally relevant to drug design. A recurring theme in this study is a view that it is generally better to observe the response of affinity to molecular size directly rather than through the distorting lens of the flawed LE metric. 


\section{MOLECULAR SIZE AND DESIGN RISK}

It is important that drug discovery scientists be fully aware of the assumptions on which the LE metric is based and that they carefully consider their motivation for using LE (or indeed any design guidelines). Property-based design [29,30] can be seen in terms of balancing the risk associated with poor physicochemical characteristics against the risk of not being able to achieve the necessary level of affinity. Ro5 [20] is based on analysis of property distributions of drugs (defined as compounds that had progressed into Phase 2 trials) and the assessment of risk is indirect because non-drugs were not included in the original analysis. Ro5 [20] neither takes account of correlations between risk factors nor does it provide a means to deconvolute the risks associated with excessive molecular size and lipophilicity. The LE metric can be seen as a simple means with which to balance risk and there are more rigorous and sophisticated ways for doing this [43]. Simple drug design guidelines based on molecular size and/or lipophilicity typically become progressively less useful as more measured data become available to the drug discovery team.

Drug design guidelines are typically based on trends observed in data and the strengths of these trends indicate how rigidly guidelines should be adhered to. While excessive molecular size and lipophilicity are widely accepted as primary risk factors in design, it is unclear how directly predictive they are of more tangible risks such as poor oral absorption, inadequate intracellular exposure and rapid turnover by metabolic enzymes. This is an important consideration because the strength of the rationale for using LE depends on the degree to which molecular size is predictive of risk. Drug discovery scientists need to be wary of correlation inflation [14] (the term voodoo correlation [44] is also used) which can be loosely defined as presentation or analysis of data in any way that makes trends appear to be stronger than they actually are. Correlation inflation is a particular concern when analysis of proprietary data is presented in support of a view that a set of guidelines is especially useful or predictive. Published analyses of relationships [40,45] between pharmacological promiscuity and molecular size and lipophilicity exemplify the problem. Comparison of average values without taking account of variance is one way in which trends can be made to appear to be stronger than they actually are and correlation inflation is acknowledged [46,47] as an issue in drug design. Variance in the dependent variable can also be hidden by representing a distribution (e.g., aqueous solubility of compounds with property forecast index in the range $6-7$ ) by a single percentile (e.g., percentage of those compounds with aqueous solubility $>200 \mu \mathrm{M}$ ) [48]. 
The relevance of data must also be considered when using physicochemical characteristics such as molecular size to assess risk. For example, an activity threshold [40] of $>30 \%$ inhibition at $10 \mu \mathrm{M}$ for promiscuity analysis is not especially relevant if considering the likelihood of off-target effects for a drug with a peak unbound plasma concentration of 100 nM. Sample bias can be significant, even in large datasets, as exemplified by divergent conclusions of two apparently similar studies $[40,45]$ with respect to the relationship between pharmacological promiscuity and molecular size. The observation that average molecular weight appears to decrease [45] with promiscuity is particularly relevant to the use of LE because promiscuity would generally be considered [40] to be an undesirable characteristic for a compound. Drug designers should not automatically assume that conclusions drawn from analysis of large, structurally-diverse data sets are necessarily relevant to the specific drug design projects on which they are working.

\section{THERMODYNAMIC ASPECTS OF LIGAND-PROTEIN ASSOCIATION}

The LE metric [1] was introduced in thermodynamic terms and it is sometimes believed that it measures the degree to which molecular interactions between ligand and target are optimal. For example, it has been asserted [49] "Because of these optimal interactions, fragments are very 'atom efficient' binders, demonstrated by high ligand efficiency'. This section focuses on thermodynamic [7,39] aspects of protein-ligand association most relevant to LE and to the interpretation of affinity in terms of molecular interactions [26,27].

The standard free energy of binding, $\Delta \mathrm{G}^{\circ}$, [39] can be written in terms of the gas constant $(\mathrm{R})$, thermodynamic temperature $(\mathrm{T}), \mathrm{C}^{\circ}$ and the equilibrium concentrations of protein $([\mathrm{P}])$, ligand ([L]), and protein-ligand complex ([P.L]):

$$
\Delta G^{\circ}=R T \ln \left(\frac{[P][L]}{[P . L] C^{\circ}}\right)
$$

Equation (2) shows that $\Delta \mathrm{G}^{\circ}$ is a function of $\mathrm{C}^{\circ}$ and this is one reason that values of standard free energy of binding should not be termed absolute. By convention, $\mathrm{C}^{\circ}$ is taken to be $1 \mathrm{M}$ although, this is arbitrary and the value of $\mathrm{C}^{\circ}$ has no physical significance [39]. In thermodynamic analysis, a change in perception resulting from a change in a standard state definition would generally be regarded as a serious error rather than a penetrating insight. In some situations, the dissociation constant, $\mathrm{K}_{\mathrm{D}}$, is defined to be equal to the argument of the logarithm in equation (2) and is therefore dimensionless. However, in medicinal chemistry, 
biochemistry and biophysics, $\mathrm{K}_{\mathrm{D}}$ values are conventionally quoted in units of concentration and equation (2) can be written as:

$$
\Delta G^{\circ}\left(T, P, C^{\circ}\right)=R T \ln \left(\frac{K_{D}(T, P)}{C^{\circ}}\right)
$$

Equation (3) shows that a tenfold increase in $\mathrm{C}^{\circ}$ leads to a decrease in $\Delta \mathrm{G}^{\circ}$ of $1.36 \mathrm{kcal} / \mathrm{mol}$ at $298 \mathrm{~K}$. The sign of $\Delta \mathrm{G}^{\circ}$ has no special significance and simply indicates whether or not $\mathrm{K}_{\mathrm{D}}$ is greater or less than $\mathrm{C}^{\circ}$. The dependence of $\Delta \mathrm{G}^{\circ}$ on $\mathrm{C}^{\circ}$ is a consequence of the stoichiometry of association of ligand with target and $\Delta \mathrm{G}^{\circ}$ for formation of a ternary complex (relevant when considering the thermodynamic consequences of fragment linking) will exhibit a different dependence on $\mathrm{C}^{\circ}$ to $\Delta \mathrm{G}^{\circ}$ for a binary complex. The stoichiometry corresponding to a $\Delta \mathrm{G}^{\circ}$ value is specified by the change, $\Delta \mathrm{N}$, in the number of species for the corresponding reaction and it can also be seen as a 'hidden dimension' of $\Delta \mathrm{G}^{\circ}$. For example, formation and dissociation of $1: 1$ complexes have $\Delta \mathrm{N}$ values of -1 and +1 respectively. The value of $\Delta \mathrm{N}$ determines the dimensions of the corresponding equilibrium constant:

$$
\operatorname{dim} K=(\text { concentration })^{\Delta N}
$$

The dependence of $\Delta \mathrm{G}^{\circ}$ on $\mathrm{C}^{\circ}$ is a consequence of the loss of translational entropy resulting from association and it has two important implications. First, ratios of $\Delta \mathrm{G}^{\circ}$ values also depend on $\mathrm{C}^{\circ}$ even though the ratios themselves are dimensionless and $\Delta \mathrm{G}^{\circ}$ values should therefore be compared as differences (i.e., $\Delta \Delta \mathrm{G}$ ). Second, if a free energy change is written as a sum of free energy changes then the sum needs to have the same dependency on $\mathrm{C}^{\circ}$ as the original free energy change since the equality must hold for all values of $\mathrm{C}^{\circ}$. This is equivalent to requiring that the sum of $\Delta \mathrm{N}$ values for the components of a free energy decomposition be equal to the $\Delta \mathrm{N}$ value for the free energy change that is decomposed. 
One way in which stoichiometry can be accounted for in free energy decompositions is to associate each free change with its corresponding $\Delta \mathrm{N}$ value using square brackets. The study by Jencks [50] (J1981) on attribution and additivity of binding energies can be used to illustrate this. J1981 [50] defines the intrinsic binding energy for a group $\mathrm{X}$ as the difference in $\Delta \mathrm{G}^{\circ}$ for compounds in which $\mathrm{X}$ is present $(\mathrm{AX})$ or absent $(\mathrm{A})$ in the relevant molecular structures:

$$
\Delta G_{X}^{i}[0]=\Delta G_{A X}^{\circ}[-1]-\Delta G_{A}^{\circ}[-1]
$$

The intrinsic binding energy is associated with a zero value of $\Delta \mathrm{N}$ and is therefore independent of $\mathrm{C}^{\circ} . \mathrm{J} 1981$ [50] writes the $\Delta \mathrm{G}^{\circ}$ value for a compound with linked groups $\mathrm{A}$ and $\mathrm{B}$ in its molecular structure as the sum of the intrinsic binding energies of $\mathrm{A}$ and $\mathrm{B}$, and the "connection Gibbs energy" $\left(\Delta \mathrm{G}^{\mathrm{s}}\right)$ :

$$
\Delta G_{A B}^{\circ}[-1]=\Delta G_{A}^{i}[0]+\Delta G_{B}^{i}[0]+\Delta G^{s}[-1]
$$

Equation (6) is particularly relevant to fragment linking and it is important to note that $\Delta \mathrm{G}^{\mathrm{s}}$ does depend on $\mathrm{C}^{\circ}[7,50]$. In some studies, $\Delta \mathrm{G}^{\circ}$ is decomposed into a value corresponding to zero molecular size $\left(\Delta \mathrm{G}_{\mathrm{MS}=0}\right)$ and a $\Delta \Delta \mathrm{G}$ value:

$$
\Delta G^{\circ}[-1]=\Delta G_{M S=0}[-1]-\Delta \Delta G[0]
$$

For example, K1999 [32] and S2007 [34] use $\Delta \mathrm{G}_{\mathrm{MS}=0}$ values of 0 and $+4.2 \mathrm{kcal} / \mathrm{mol}$ respectively. While this decomposition is valid to the extent that the sum has same dependence on $\mathrm{C}^{\circ}$ as $\Delta \mathrm{G}^{\circ}$, the assignment of an affinity value (e.g., $\left.\mathrm{K}_{\mathrm{D}}=1 \mathrm{M}\right)$ to a solute of zero molecular size for efficiency calculations does not appear to have any physical basis.

One general approach to modelling affinity is to use equation (8) in which $A_{i}(i>0)$ is a parameter associated with the substructure $i$ and $n_{i}$ is the number of occurrences of that substructural element:

$$
\Delta G^{\circ}[-1]=A_{0}[-1]+\sum_{i=1}^{N_{S S}} n_{i} \times A_{i}[0]
$$

The $\mathrm{A}_{0}$ term has the same dependency on $\mathrm{C}^{\circ}$ as $\Delta \mathrm{G}^{\circ}$ and its inclusion in equation (8) allows changes in concentration unit to be easily accounted for. In Free-Wilson analysis [51] the substructures are typically groups at substitution sites on a scaffold and the $n_{i}$ values are either 
1 or 0 and $A_{0}$ may correspond to the affinity of the unsubstituted scaffold. In the analysis of functional group contributions by Andrews, Craik and Martin (ACM1984) [52], $\mathrm{A}_{0}$ corresponds to the entropy term which was set to $-14 \mathrm{kcal} / \mathrm{mol}$ rather than derived by fitting the data. Schemes for decomposition of $\Delta \mathrm{G}^{\circ}$ based on equation (8) cannot be considered to be group additive because of the presence of the $A_{0}$ term which is not associated with any group.

It has been asserted [53] that "Ligand efficiency can be recast as a special case of group additivity where $\triangle G / H A$ is the group equivalent" but this does not properly account for the stoichiometry of the binding. Unlike is equation (8), there is no is $A_{0}$ term when $\Delta G^{\circ}(\Delta N=$ -1 ) is decomposed into a sum of $\mathrm{N}_{\mathrm{nH}}$ equal atom-based terms and this leads to significant difficulties. Specifically, each term in the sum must have an identical dependence on $\mathrm{C}^{\circ}$ while the sum of terms needs to reproduce the dependence of $\Delta \mathrm{G}^{\circ}$ on $\mathrm{C}^{\circ}$. While this can be achieved algebraically by assigning a fractional stoichiometry to each atom-based term, the physical meaning of the resulting atom-based terms remains obscure. For example, the numerical values that result from dividing $\Delta \mathrm{G}^{\circ}$ values of $5 \mathrm{kcal} / \mathrm{mol}$ and $10 \mathrm{kcal} / \mathrm{mol}$ by 10 and 20 respectively are identical. However, the two quantities cannot be equated because they differ in their dependence on $\mathrm{C}^{\circ}$. In contrast, the enthalpy of binding, $\Delta \mathrm{H}$, does not depend on $\mathrm{C}^{\circ}$ and so enthalpic efficiency [54] can be defined unambiguously.

An equivalent way to examine the stoichiometry issue is to consider the implications of writing $\mathrm{K}_{\mathrm{D}}$ as follows where $\mathrm{k}_{\mathrm{nH}}$ corresponds to $\Delta \mathrm{g}$ as defined in equation (1):

$$
K_{D}=\left(k_{n H}\right)^{N_{n H}}
$$

Consider two compounds $X\left(K_{D}=10^{-3} \mathrm{M} ; N_{n H}=10\right)$ and $Y\left(K_{D}=10^{-6} M ; N_{n H}=20\right)$ that would usually be considered to be equally ligand-efficient $(\Delta \mathrm{g}=0.4 \mathrm{kcal} / \mathrm{mol}$ per non-hydrogen atom at $298 \mathrm{~K}$ for $\left.\mathrm{C}^{\circ}=1 \mathrm{M}\right)$. While the values of $\mathrm{k}_{\mathrm{nH}}$ calculated for $\mathrm{X}\left(0.501 \mathrm{M}^{0.1}\right)$ and $\mathrm{Y}(0.501$ $\mathrm{M}^{0.05}$ ) have the same numerical value, it is incorrect to equate them because their dimensions differ, as reflected by the difference in their respective units. If $K_{D}$ is expressed in millimolar units, the numerical values of $\mathrm{k}_{\mathrm{nH}}$ for $\mathrm{X}\left(1 \mathrm{mM}^{0.1}\right)$ and $\mathrm{Y}\left(0.708 \mathrm{mM}^{0.05}\right)$ are no longer identical.

The need to properly account for stoichiometry is one reason that the contribution of an intermolecular contact (or a substructure) to affinity is not an experimental observable [8] although this appears to be the case even when stoichiometry is not an issue [28]. Some of the entropy of binding results from molecular interactions (e.g., between water molecules) that are 
non-local with respect to protein-ligand contacts. Some contributions to binding enthalpy, such as the enthalpic penalties associated with ligand and target adopting their bound conformations are also inherently non-local. A less obvious example of a non-local effect would be substitution at one position of a molecular structure preventing a substituent at another position from forming optimal interactions with the target. When interpreting binding thermodynamics in terms of molecular interactions, it should always be kept in mind that intermolecular contacts (e.g., between unbound ligand and solvent) that are not present in the protein-ligand complex also influence $\Delta \mathrm{H}$ and $\Delta \mathrm{S}^{\circ}$.

Target interaction potential (TIP) can be a helpful concept when considering association of ligands with their targets. TIP takes account of both the nature of the interactions (e.g., hydrogen bonds) and the fact that ligand-target association takes place in an aqueous environment. Hotspots [55] on the molecular surface of a target can be seen as regions of high TIP while ligandability [56] is determined both by the magnitude of TIP and the extent to which it can be exploited. An ability to reversibly form covalent bonds (e.g., catalytic cysteine thiol or a protein-bound metal cation such as zinc) with ligands would generally be associated with high TIP as would depletion [57] of water from a binding pocket or the "frustrated" hydration [42] resulting from the overlap of solvation spheres of adjacent hydrogen bond donors (or acceptors). A key challenge in drug design is to determine whether inadequate affinity is due to low TIP (i.e., target is the problem) or underexploited TIP (i.e., compound is the problem).

\section{PERCEPTION OF AFFINITY VARIES WITH CONCENTRATION UNIT}

Although the implications for $\mathrm{LE}$ of the dependence of $\Delta \mathrm{G}^{\circ}$ on $\mathrm{C}^{\circ}$ were first highlighted [7] in 2009 by Zhou and Gilson, they have been overlooked by LE advocates. For example, Murray et al (M2014) [58] discussed the validity of LE but demonstrated no awareness of the relevance of the dependence of $\Delta \mathrm{G}^{\circ}$ on $\mathrm{C}^{\circ}$. A Future Medicinal Chemistry editorial [59] claimed that "Ligand efficiency validated fragment-based design" while reassuring its readers that "There is no need to become overly concerned with noisy arguments for or against ligand efficiency metrics being exchanged in the literature." However, this editorial [59] neither makes reference to criticism [7] of LE made in 2009 nor does it address the implications [8] of the nontrivial dependence of the metric on what is an entirely arbitrary concentration unit. 
Some of the problems that result from using LE as a design metric can be seen more clearly if it is expressed using a base 10 logarithm and without energy units:

$$
\eta_{\text {bind }}=-\left(\frac{1}{N_{n H}}\right) \times \log _{10}\left(\frac{K_{D}}{C^{\circ}}\right)=\frac{\Delta g}{R T \ln (10)}
$$

The quantity $\eta_{\text {bind }}$ is related to $\Delta \mathrm{g}$ by a multiplicative factor of $\mathrm{RT} \ln (10)$ that is independent of $\mathrm{C}^{\circ}$ and therefore both quantities respond in an identical manner to a change in $\mathrm{C}^{\circ}$. One rationale for using $\eta_{\text {bind }}$ is that drug discovery scientists typically use $\mathrm{pIC}_{50}$ or $\mathrm{pK} \mathrm{D}_{\mathrm{D}}$ rather than $\Delta \mathrm{G}^{\circ}$ in SAR analysis. The quantity $\eta_{\text {bind }}$ is also related to ligand efficiency by atomic number (LEAN) [60] that is calculated by scaling $\mathrm{pIC}_{50}$ by $\mathrm{N}_{\mathrm{nH}}$. Unlike LEAN, $\eta_{\text {bind }}$ is a function of $\mathrm{C}^{\circ}$ and can also be written as $\eta_{\text {bind }}\left(\mathrm{C}^{\circ}\right)$ to emphasize this. Although standard state conventions do not apply to potency measures such as $\mathrm{IC}_{50}$ and $\mathrm{EC}_{50}$, which are usually quoted in $\mu \mathrm{M}$ or $\mathrm{nM}$, potency must still be scaled by a concentration value for the logarithm calculation because the logarithm function is not defined for dimensioned quantities [9]. Using $\eta_{\text {bind }}$ rather than $\Delta \mathrm{G}^{\circ}$ reinforces the point that the problems associated with LE are due to the mathematical behavior of the logarithm function. While the use of a concentration unit other than $1 \mathrm{M}$ to define LE is unusual, there certainly is precedent for doing so. For example, minimum inhibitory concentration, used to define antibacterial efficiency [61], was scaled by $\mathrm{mg} / \mathrm{ml}$ in order that the logarithm could be calculated.

Table 1 illustrates how a change in $\mathrm{C}^{\circ}$ alters the perception of efficiency. The hypothetical set of three compounds consists of a fragment hit $\left(\mathrm{N}_{\mathrm{nH}}=10 ; \mathrm{K}_{\mathrm{D}}=1 \mathrm{mM}\right)$, a lead $\left(\mathrm{N}_{\mathrm{nH}}=20 ; \mathrm{K}_{\mathrm{D}}\right.$ $=1 \mu \mathrm{M})$ and a clinical candidate $\left(\mathrm{N}_{\mathrm{nH}}=30 ; \mathrm{K}_{\mathrm{D}}=1 \mathrm{nM}\right)$ that would usually be regarded as equally ligand-efficient $\left(\Delta \mathrm{g}=0.4 \mathrm{kcal} / \mathrm{mol}\right.$ per non-hydrogen atom at $298 \mathrm{~K}$ for $\left.\mathrm{C}^{\circ}=1 \mathrm{M}\right)[8]$. An identical $\eta_{\text {bind }}$ value of 0.3 per non-hydrogen atom is indeed calculated for all three compounds when $\mathrm{C}^{\circ}$ is set to the conventional value of $1 \mathrm{M}$. Using a value of $0.1 \mathrm{M}$ for $\mathrm{C}^{\circ}$ leads to the conclusion that the clinical candidate is more ligand-efficient than the fragment but, if $\mathrm{C}^{\circ}$ is set to $10 \mathrm{M}$, we come to the opposite conclusion. Given that rankings of compounds can change with $\mathrm{C}^{\circ}$ and that there is no way of objectively selecting a value of $\mathrm{C}^{\circ}$ for these calculations, neither $\eta_{\text {bind }}$ nor $\Delta \mathrm{g}$ would appear to be fit for the purpose of assessing performance, potential or quality of compounds in drug discovery projects. An analogous

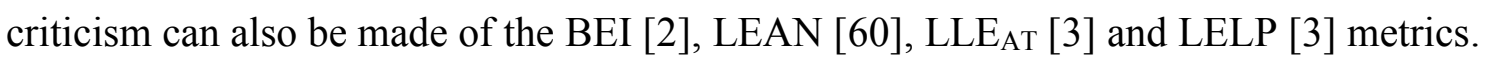


Table 1. Dependence of ligand efficiency on $\mathrm{C}^{\circ}$

\begin{tabular}{|l|l|l|l|l|}
\hline & & \multicolumn{3}{|c|}{$\eta_{\text {bind }}\left(\mathrm{C}^{\circ}\right)^{\mathrm{a}}$} \\
\hline $\mathrm{N}_{\mathrm{nH}}{ }^{\mathrm{b}}$ & $\mathrm{K}_{\mathrm{D}} / \mathrm{M}^{\mathrm{c}}$ & $\mathrm{C}^{\circ}=0.1 \mathrm{M}$ & $\mathrm{C}^{\circ}=1 \mathrm{M}$ & $\mathrm{C}^{\circ}=10 \mathrm{M}$ \\
\hline 10 & $10^{-3}$ & 0.20 & 0.30 & 0.40 \\
\hline 20 & $10^{-6}$ & 0.25 & 0.30 & 0.35 \\
\hline 30 & $10^{-9}$ & 0.27 & 0.30 & 0.33 \\
\hline
\end{tabular}

${ }^{\text {a }}$ Ligand efficiency defined in (10)

${ }^{b}$ Number of non-hydrogen atoms in molecular structure

${ }^{c}$ Dissociation constant for protein-ligand complex

The change in perception of efficiency that results from a change in $\mathrm{C}^{\circ}$ shows that neither $\eta_{\text {bind }}$ nor $\Delta \mathrm{g}$ has thermodynamic significance. A necessary, but not sufficient, condition for validity of thermodynamic analysis is that conclusions drawn from the analysis cannot depend on the choice of $\mathrm{C}^{\circ}$. Although $\mathrm{C}^{\circ}$ is an integral component of the framework of solution thermodynamics, it can also be seen simply as a unit used to express affinity so that a logarithm can be calculated for $\mathrm{K}_{\mathrm{D}}$. A physical quantity that is expressed in different units is still the same quantity. If perception changes when a quantity is expressed using a different unit then neither the change in perception nor the quantity itself can be regarded as physically meaningful. Provided that $\mathrm{C}^{\circ}$ is known, $-\log \left(\mathrm{K}_{\mathrm{D}} / \mathrm{C}^{\circ}\right)$ is physically meaningful and the effect of a change in $\mathrm{C}^{\circ}$ is both constant and calculable. In contrast, knowing values of $\eta_{\text {bind }}$ and $\mathrm{C}^{\circ}$ does not allow us to calculate the $\eta_{\text {bind }}$ value corresponding to another value of $\mathrm{C}^{\circ}$. Furthermore, the results presented in Table 1 show that a single $\eta_{\text {bind }}$ value can transform to more than one $\eta_{\text {bind }}$ value in response to a change in $\mathrm{C}^{\circ}$.

The change in perception resulting from a change of unit raises the question of whether or not LE can accurately be described as a metric. The defining characteristic of a metric is that it measures and it is necessary to state clearly what a quantity measures if claiming that the quantity is a metric. While units are essential for measurement, a valid and credible framework for measurement must allow for quantities to be expressed in different units (e.g. $\mu \mathrm{M}$ and $\mathrm{nM}$ ). For example, readers might consider their likely responses to a hypothetical report that the space group for a crystal structure differed according to whether unit cell parameters were 
expressed in Ångstrom or in nanometer units. There are two reasons that LE should not be considered to be a metric. First, it is not clear what LE measures since neither the extent to which molecular interactions are optimal nor interaction quality are experimental observables. Second, LE has a unit (1 M) built into it and perception of efficiency is altered (Table 1) when another concentration unit is used. It would actually be more accurate to describe LE as a simple predictor of potency in cell-based assays or of in vivo activity that, like property forecast index [48], has neither been validated nor optimized for prediction.

A

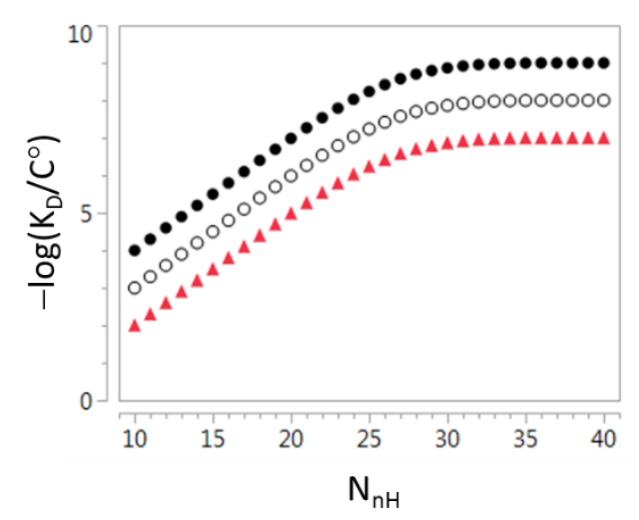

$\mathrm{B}$

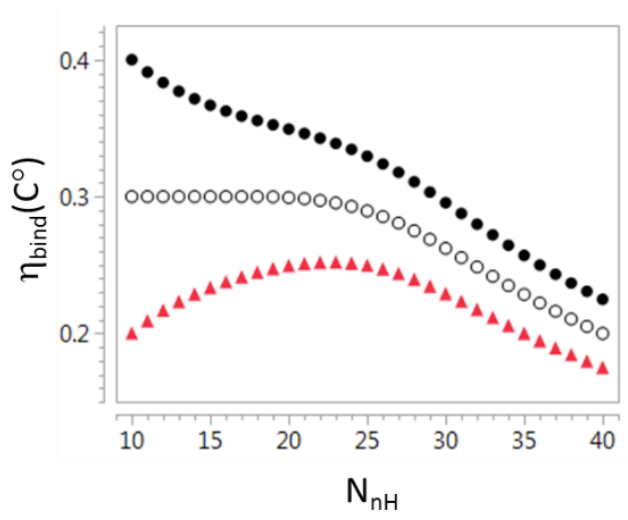

Key: $\bullet\left(\mathrm{C}^{\circ}=1 \mathrm{M}\right) \quad \circ\left(\mathrm{C}^{\circ}=0.1 \mathrm{M}\right) \quad \Delta\left(\mathrm{C}^{\circ}=0.01 \mathrm{M}\right)$

Figure 1. (A) Response of affinity to molecular size for plotted for three different $\mathrm{C}^{\circ}$ values (B) Plot of LE ( $\eta_{\text {bind }}$ ) calculated from the response of affinity to molecular size using three different $\mathrm{C}^{\circ}$ values

Figure 1 illustrates the impact of the dependence of $\eta_{\text {bind }}$ on $\mathrm{C}^{\circ}$ in an alternative manner to Table 1. Figure 1A shows a hypothetical response of affinity to $\mathrm{N}_{\mathrm{nH}}$ that has been constructed to have a linear region (slope $=0.3$ per non-hydrogen atom) at low $\mathrm{N}_{\mathrm{nH}}$ and a plateau at high $\mathrm{N}_{\mathrm{nH}}$. The response is plotted for three different values $(1 \mathrm{M} ; 0.1 \mathrm{M} ; 0.01 \mathrm{M})$ of $\mathrm{C}^{\circ}$ and this shows how expressing affinity in a different unit shifts the entire response by a constant amount without affecting the shape of the response. In contrast, using a different unit to express $\eta_{\text {bind }}$ actually changes the shape of the response of $\eta_{\text {bind }}$ to $\mathrm{C}^{\circ}$. Furthermore, transformation of affinity to $\eta_{\text {bind }}$ typically makes it more difficult to perceive the linear and plateau regions of the response of affinity to $\mathrm{N}_{\mathrm{nH}}$. The results presented in Figure 1 highlight the importance of observing relationships between affinity and molecular size directly. 
LE is used to specify affinity cutoffs as a function of molecular size and a $\Delta \mathrm{g}$ value of 0.3 $\mathrm{kcal} / \mathrm{mol}$ per non-hydrogen atom has been suggested [3]. Specification of affinity cutoffs in this manner forces the line defining acceptable affinity to intersect the affinity axis at a point corresponding to a $\mathrm{K}_{\mathrm{D}}$ value of $1 \mathrm{M}$. This causes considerable difficulties when the range in $\mathrm{N}_{\mathrm{nH}}$ is large as is the case for beyond rule of 5 (bRo5) [62] compounds. The minimum $\Delta \mathrm{g}$ value of $0.12 \mathrm{kcal} / \mathrm{mol}$ per non-hydrogen atom recommended [62] for bRo5 compounds can be translated $\left(\mathrm{C}^{\circ}=1 \mathrm{M} ; \mathrm{T}=300 \mathrm{~K}\right)$ to $\mathrm{pK}$ D values corresponding to the lower $\left(700 \mathrm{Da} ; \mathrm{N}_{\mathrm{nH}} \approx 50\right)$ and upper (3000 Da; $\left.\mathrm{N}_{\mathrm{nH}} \approx 214\right)$ limits for bRo5 space. The lower $\left(\mathrm{pK} \mathrm{D}_{\mathrm{D}}=4.4\right)$ of these two values would not appear to be a useful design criterion while the higher value $\left(\mathrm{pK} \mathrm{D}_{\mathrm{D}}=18.7\right)$ would not generally be measurable. In general, affinity thresholds should be specified directly and LE should only be used for this purpose if supported by the data.

LE was introduced [1] with the claim that it was useful but it is rarely, if ever, shown to be predictive of pharmaceutically-relevant behavior. As such, the utility of LE as a design metric hinges on it being meaningful and there is a burden of proof on those who advocate the use of LE to demonstrate that their choice of unit is universally appropriate. The importance of physicochemical properties is widely accepted in drug design and many medicinal chemists would regard it as routine to monitor progress in projects by plotting potency against molecular size or lipophilicity. A critique of LE metrics actually emphasized the importance of modeling relationships between affinity and risk factors for compounds of interest [8]. However, a depiction [6] of an optimization path for a project that has achieved a satisfactory endpoint is not direct evidence that consideration of molecular size or lipophilicity made a significant contribution toward achieving that endpoint. Furthermore, explicit consideration of lipophilicity and molecular size in design does not mean that efficiency metrics were actually used for this purpose. Design decisions in lead optimization are typically supported by assays for a range of properties such as solubility, permeability, metabolic stability and off-target activity as well as pharmacokinetic studies. This makes it difficult to assess the extent to which efficiency metrics have actually been used to make decisions in specific projects, especially given the proprietary nature of much project-related data. 


\section{LIGAND EFFICIENCY AND FRAGMENT-BASED DESIGN}

LE features prominently in the literature of fragment-based lead discovery (FBLD) [63-68] to the extent that it is sometimes presented as an important rationale for screening fragments. For example, it has been claimed [64] that "fragment hits typically possess high 'ligand efficiency' (binding affinity per heavy atom) and so are highly suitable for optimization into clinical candidates with good drug-like properties". It has been asserted [31] that "fragment hits form high-quality interactions with the target" although it is not clear if interaction quality involves aesthetic aspects in addition to the physical forces more usually associated with molecular recognition [26,27]. I would argue that the rationale for screening fragments against targets of interest is actually based on two conjectures. First, chemical space can be covered most effectively by fragments because compounds of low molecular complexity [18,21,22] allow TIP to be explored [69-73] more efficiently and accurately. Second, a fragment that has been observed to bind to a target may be a better starting point for design than a higher affinity ligand whose greater molecular complexity prevents it from presenting molecular recognition elements to the target in an optimal manner. While proving either conjecture definitively is difficult, the success [74] of fragment-based approaches indicate that the underlying assumptions are reasonable.

The Johnson et al 2018 study (J2018) [75] examined start-finish differences in LE for a number for a number of fragment-to-lead (F2L) optimizations that had been published in 2016 and there is precedent [48] for analyzing start-finish differences for projects in this manner. J2018 [75] notes that differences in LE between fragment hits and leads were not statistically significant and states that "in contrast to anecdotal reports that LE tends to decline during the F2L process, LE decreased during optimization for only a minority of examples". This analysis is repeated using $\Delta \eta_{\text {bind }}$ values calculated for different values of $\mathrm{C}^{\circ}$ ranging from $0.001 \mathrm{M}$ to $10 \mathrm{M}$ and the results are summarized in Table 2. As $\mathrm{C}^{\circ}$ increases, the leads appear to become less ligand-efficient in comparison with the fragment hits from which they had been derived and this is analogous to what is shown in Table 1. Statistically significant differences between values for fragment hits and leads are only observed if $\mathrm{C}^{\circ}$ is $0.01 \mathrm{M}$ or $0.001 \mathrm{M}$. 
Table 2. Dependence on $\mathrm{C}^{\circ}$ of mean changes in ligand efficiency for F2L programs surveyed in $\mathrm{J} 2018$

\begin{tabular}{|l|l|l|l|}
\hline $\mathrm{C}^{\circ} / \mathrm{M}^{\mathrm{a}}$ & Mean $\Delta \eta_{\text {bind }^{\mathrm{b}}}$ & $\mathrm{SE} \Delta \eta_{\text {bind }^{\mathrm{c}}}$ & Prob $>|\mathrm{t}|^{\mathrm{d}}$ \\
\hline 0.001 & +0.087 & 0.012 & $<0.001$ \\
\hline 0.01 & +0.055 & 0.015 & 0.001 \\
\hline 0.1 & +0.024 & 0.018 & 0.20 \\
\hline 1.0 & -0.008 & 0.021 & 0.69 \\
\hline 10 & -0.04 & 0.024 & 0.11 \\
\hline
\end{tabular}

${ }^{a}$ Standard concentration

${ }^{\mathrm{b}}$ Mean change in ligand efficiency as defined in (10)

${ }^{c}$ Standard error in mean change in ligand efficiency as defined in (10)

${ }^{\mathrm{d}} \mathrm{P}$ value for matched pair $\mathrm{t}$ test

Comparison of LE values for fragment hits and the corresponding leads can be seen as an attempt to quantify how effectively an increase in molecular size translates to affinity gain over the course of an F2L project. This is still a valid objective even though the LE metric would appear to be unfit for this purpose. The most obvious way to do this is to scale $\Delta \mathrm{pK}$ D by $\Delta \mathrm{N}_{\mathrm{nH}}$ for the F2L pairs:

$$
\frac{\Delta p K_{D}}{\Delta N_{n H}}=\left(\frac{1}{N_{n H}[L]-N_{n H}[F]}\right) \times \log _{10}\left(\frac{K_{D}[F]}{K_{D}[L]}\right)
$$

The quantity defined in equation (11) can regarded as a measure of MSE for the F2L optimization. Using $\Delta \mathrm{pK}$ (the logarithm of a ratio of $K_{D}$ values) eliminates the dependency on $\mathrm{C}^{\circ}$ that makes $\Delta \eta_{\text {bind }}$ (and $\Delta \mathrm{g}$ ) unsuitable for comparison of start and end points for projects. An additional benefit is that $\Delta \mathrm{pK}_{\mathrm{D}}$ is likely to be relatively insensitive to the approximation of $\mathrm{K}_{\mathrm{D}}$ by $\mathrm{IC}_{50}$. This approach to assessing optimizations has precedent and H2006 [33] reported that a tenfold improvement in $K_{D}$ corresponded to a mean increase in molecular weight of 64 $\mathrm{Da}$ (standard deviation $=18 \mathrm{Da}$ ) for 73 compound pairs from FBLD projects. H2006 [33] also illustrates the benefit of observing the response of affinity to an increase in molecular size directly rather than indirectly by using the LE metric. 
It can be useful to compare the changes in affinity and lipophilicity that result from structural elaboration and one way of achieving this is to offset the change in affinity by change in lipophilicity:

$$
\Delta p K_{D}-\Delta \log P=\log _{10}\left(\frac{K_{D}[F] \times P[F]}{K_{D}[L] \times P[L]}\right)
$$

The quantity in equation (12) may be regarded as a measure of the lipophilicity efficiency for the F2L optimization and is equivalent to the change in what would be termed LLE $[3,40]$ or LipE [41]. It is desirable that it should be as large as possible for F2L projects. Variations of equation (12) can also be written using potency (e.g. pIC $\mathrm{f}_{50}$ ) with a measured distribution coefficient $(\log \mathrm{D})$ or a predicted [76] value of $\log \mathrm{P}$. Where $\mathrm{pK}_{\mathrm{D}}$ was not available, it has been approximated by $\mathrm{pIC}_{50}$ and the $\mathrm{Clog} \mathrm{P}$ values reported in $\mathrm{J} 2018$ [75] are used as the measure of lipophilicity.

A plot of $\Delta \mathrm{pK} \mathrm{D}_{\mathrm{D}}$ against $\Delta \mathrm{N}_{\mathrm{nH}}$ with reference lines of constant $\left(\Delta \mathrm{pK} \mathrm{D} / \Delta \mathrm{N}_{\mathrm{nH}}\right)$ is shown in Figure 2A. This depiction is intended to map the distribution of $\left(\Delta \mathrm{pK} \mathrm{D} / \Delta \mathrm{N}_{\mathrm{nH}}\right)$ values so the reference lines are drawn to mark quartiles rather than at equally-spaced intervals. A plot of $\left(\Delta \mathrm{pK}_{\mathrm{D}}-\Delta \mathrm{Clog} \mathrm{P}\right)$ against $\Delta \mathrm{N}_{\mathrm{nH}}$ is shown in Figure $2 \mathrm{~B}$ with reference lines to map the distribution. Affinity gains for optimizations with zero values of $\left(\Delta \mathrm{pK} \mathrm{D}_{\mathrm{D}}-\Delta \mathrm{Clog} \mathrm{P}\right)$ would typically be regarded as being entirely due to increased hydrophobic contact with target. However, it is important to be aware that the octanol/water partitioning system is relatively insensitive to the presence of hydrogen bond donors [14,42]. Large positive values of $\left(\Delta \mathrm{pK} \mathrm{D}_{\mathrm{D}}-\right.$ $\Delta \mathrm{Clog}$ ) might be considered to be evidence that the optimization process has introduced additional polar interactions although polar functionality can still be tolerated, for example by being exposed to solvent, without actually making contact with target. 
A

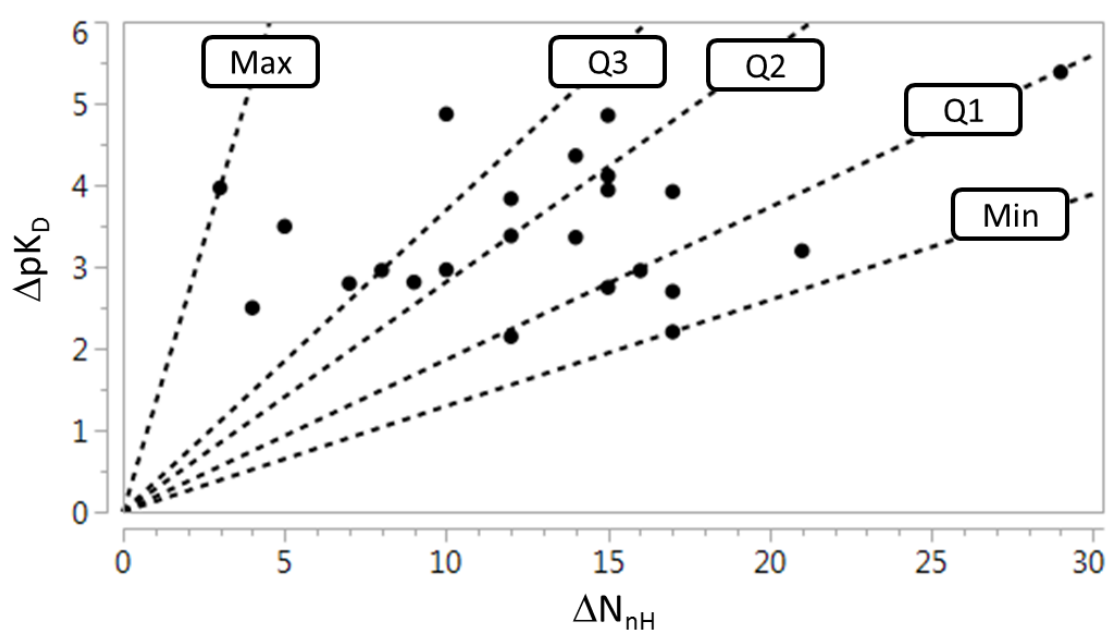

B

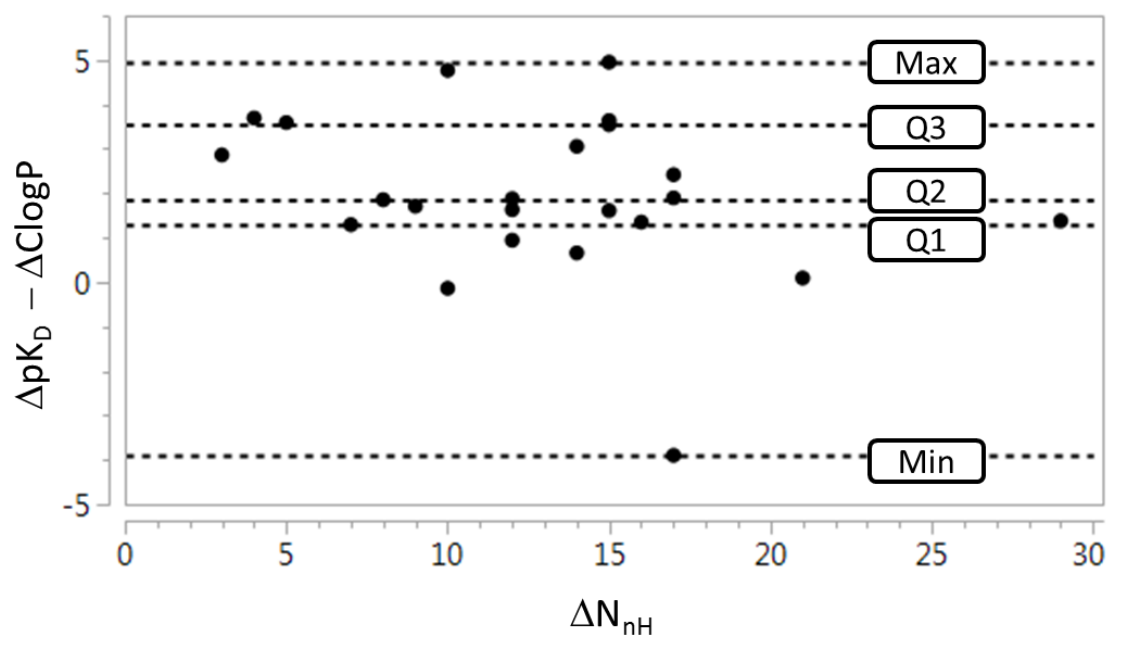

Figure 2. (A) Plot of $\Delta \mathrm{pK}$ D against $\Delta \mathrm{N}_{\mathrm{nH}}$ for J2018 F2L optimizations showing reference lines for minimum $(\min =0.13)$, first quartile $(\mathrm{Q} 1=0.18)$, median $(\mathrm{Q} 2=0.28)$, third quartile $(\mathrm{Q} 3=$ $0.37)$ and maximum $(\max =1.32)$ values of $\left(\Delta \mathrm{pK}_{\mathrm{D}} / \Delta \mathrm{N}_{\mathrm{nH}}\right)(\mathrm{B}) \mathrm{Plot}$ of $\left(\Delta \mathrm{pK} \mathrm{D}_{\mathrm{D}}-\Delta \mathrm{Clog} \mathrm{P}\right)$ against $\Delta \mathrm{N}_{\mathrm{nH}}$

An observation that can be made about the J2018 [75] analysis is that the start points for 15 of the 28 F2L projects surveyed do not appear to comply with the rule of 3 (Ro3) [77] if Ro5 [20] hydrogen bond definitions are used. This would appear to contradict the claim [74] that "Most libraries consist of molecules that adhere to the 'rule of three'." It has been suggested [22,78] that Ro3 [77] may be overly restrictive and applying the rule in this manner would eliminate carboxylic acid bioisosteres [79] such as tetrazole [80] and $\mathrm{N}$-acylsulfonamide [81] as well as the isocytosine fragment hit [82] that led to the discovery of potent $\beta$-secretase 
inhibitors [83]. All lead compounds surveyed in J2018 [75] are of greater molecular size than the corresponding fragments but this is not the case for lipophilicity. Calculated logP values for five of the leads were lower than for the fragment hits from which they were derived, suggesting that a $\log \mathrm{P}$ cutoff value of 3 may be overly restrictive for design of compound libraries for FBLD. The Ro5 [20] cutoff values for molecular weight (500 Da) and $\log \mathrm{P}(5)$ were directly derived from the relevant data since they correspond to specific percentiles in the distributions observed for these quantities. However, it should not automatically be assumed that there is an analogous correspondence between the Ro3 [77] cutoff values for molecular weight (300 Da) and $\log \mathrm{P}(3)$.

\section{GROUP EFFICIENCY}

Medicinal chemists typically view SAR in terms of affinity differences resulting from structural modifications. Observation that a small structural change leads to a large change in affinity is usually informative. Group efficiency (GE) [34] is defined for the addition of a group, $\mathrm{X}$, to $\mathrm{A}$ by scaling the value of the associated $\Delta \Delta \mathrm{G}\left(\Delta G_{X}^{i}\right.$ as defined in [50]) by $\Delta \mathrm{N}_{\mathrm{nH}}$ :

$$
G E[A \rightarrow A X]=-\left(\frac{\Delta \Delta G[A \rightarrow A X]}{\Delta N_{n H}[A \rightarrow A X]}\right)
$$

The notation $[\mathrm{X} \rightarrow \mathrm{Y}]$ can be used to specify structural transformations and to indicate that a change in the value of a property such as $\Delta \mathrm{G}^{\circ}, \mathrm{pK}_{\mathrm{D}}$ or $\mathrm{N}_{\mathrm{nH}}$ has been calculated by subtracting the value of the property for compound $\mathrm{X}$ from that for compound $\mathrm{Y}$ [84]. The definition of GE expresses equation (11) in terms of free energy rather than dissociation constant and equation (12) could be used in an analogous manner to specify the efficiency of substitutions from the perspective of lipophilicity. GE was stated [85] to be "a more sensitive metric to define the quality of an added group than a comparison of the LE of the parent and newly formed compounds" and the introduction of the metric can be seen as an attempt to address a perceived deficiency in LE. The more fundamental difference between the two metrics is that GE is independent of $\mathrm{C}^{\circ}$ because it is defined in terms of $\Delta \Delta \mathrm{G}$. Although GE is sometimes presented as a substructural (e.g. chloro substituent) property, it is actually structural transformations (e.g. substitute hydrogen with chlorine) with which values of GE should be associated. The $\Delta \Delta \mathrm{G}$ values used for calculation of GE cannot generally be interpreted as substructural contributions to affinity because summation of values of $\Delta \Delta \mathrm{G}(\Delta \mathrm{N}=0)$ cannot reproduce the dependency of $\Delta \mathrm{G}^{\circ}(\Delta \mathrm{N}=-1)$ on $\mathrm{C}^{\circ}$. 
The GE analysis in S2007 [34] was performed using data from a fragment growing project directed against protein kinase $\mathrm{B}$ (PKB) that is summarized in Figure 3. The $\Delta \mathrm{G}^{\circ}$ values in S2007 had been calculated from $\mathrm{IC}_{50}$ measurements and, in one case (1), $\mathrm{K}_{\mathrm{D}}$ estimated from crystallographic occupancy [34]. The structural prototype $\mathbf{1}\left(\mathrm{N}_{\mathrm{nH}}=5\right)$ that defines the series, is included in the data set although it was not the initial screening hit. Affinity measurements are rare for fragments of this size and are particularly valuable for mapping biophysical limits of binding. The slope of the line joining each pair of results in Figure 3B indicates the sensitivity of affinity to an increase in molecular size for each structural transformation and in some cases this is equal to GE. Compound $\mathbf{5}$ is racemic and so $[\mathbf{5} \rightarrow \mathbf{6}]$ can be considered to be a composite transformation consisting of both chloro-substitution and chiral resolution. The $\left(\Delta \mathrm{pIC}{ }_{50} / \Delta \mathrm{N}_{\mathrm{nH}}\right)$ value of 0.37 per non-hydrogen atom for $[\mathbf{3} \rightarrow \mathbf{6}]$ would place it on the Q3 reference line for the F2L optimizations surveyed in J2018 [75].

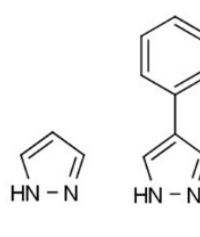

12

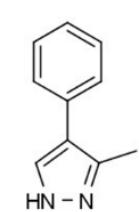

3

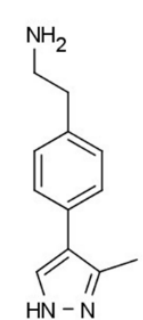

4
A

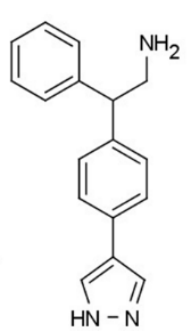

5

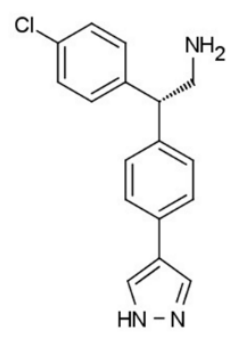

6<smiles>NCC(c1ccccc1)c1ccc(Cl)cc1</smiles>

7

B

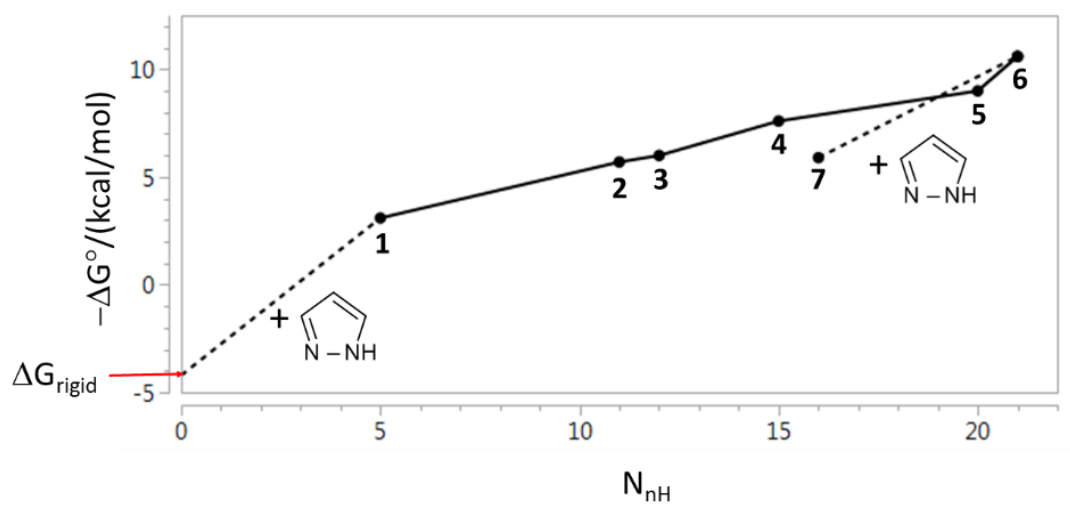

Figure 3. (A) Compounds described in $\mathrm{S} 2007$ [75] group efficiency study (B) Plot of $-\Delta \mathrm{G}^{\circ}$ against $\mathrm{N}_{\mathrm{nH}}$; broken lines indicate steps corresponding to addition of pyrazole. 
S2007 [34] reports a GE value of $1.5 \mathrm{kcal} / \mathrm{mol}$ per non-hydrogen atom for the structural prototype $\mathbf{1}$. The substructural transformation leading to $\mathbf{1}$ poses special difficulties for $\Delta \Delta \mathrm{G}$ calculation since this requires that an affinity value be assigned to a species of zero molecular size. The $\Delta \Delta \mathrm{G}$ value for this transformation was derived [34] by subtracting an estimate for rigid body entropy $\left(\Delta \mathrm{G}_{\text {rigid }}=4.2 \mathrm{kcal} / \mathrm{mol}\right)$ lost on binding from the $\Delta \mathrm{G}^{\circ}$ value for 1 . The large GE value calculated for $\mathbf{1}$ is presented [34] as evidence that the interactions of pyrazole substructure with the PKB make a particularly large contribution to affinity. One interpretation of the analysis presented in S2007 [34] appears to be that to be that the molecular interactions of the pyrazole substructure of $\mathbf{6}$ are assigned full credit for overcoming the penalties resulting from loss of translational and rotational entropy. This interpretation appears to be based on two assumptions. First, $\mathbf{1}$ and $\mathbf{6}$ lose identical amounts of rigid body entropy when they bind to PKB. Second, the pyrazole substructure makes identical interactions with the protein when 1 and 6 bind to PKB.

In SAR analysis, it would not be considered generally feasible to infer the importance of a substructure as a determinant of affinity using only measurements for compounds in which the substructure is conserved. Calculation of GE for $\mathbf{1}$ appears to require that a value of $K_{D}$ be assigned to a species of zero molecular size. The value of GE derived in this manner is determined just as much by the affinity assumed for the zero molecular size species as by the affinity that is actually measured for the compound. The $\Delta \mathrm{G}^{\circ}$ values for $7(-5.9 \mathrm{kcal} / \mathrm{mol})$ and $6(-10.6 \mathrm{kcal} / \mathrm{mol})$ can also be used to derive a GE value of $(0.9 \mathrm{kcal} / \mathrm{mol}$ per non-hydrogen atom) for the addition of the pyrazole to 6 . It is unclear why the GE value of $1.5 \mathrm{kcal} / \mathrm{mol}$ per non-hydrogen atom is preferred to the value of $0.9 \mathrm{kcal} / \mathrm{mol}$ per non-hydrogen atom that can be derived from the $\Delta \mathrm{G}^{\circ}$ values measured for $\mathbf{6}$ and $\mathbf{7}$.

The F2L optimization in S2007 [34] is essentially a sequence of substitutions and $\Delta \Delta \mathrm{G}$ values can be associated with structural modifications in a consistent manner. Drug design frequently consists of optimization of groups at two or more substitution sites on a scaffold and nonadditive [86-91] SAR needs to be considered. Free and Wilson [51] were fully aware of the problems that can result from non-additive SAR and it is not possible to assign $\Delta \Delta \mathrm{G}$ values (and therefore GE values) in a consistent manner to individual structural modifications if SAR is non-additive. Subadditive SAR should be should be anticipated whenever there is a high degree of constraint in the system and might be considered to be a natural consequence of high 
molecular complexity [18]. Structural features likely to constrain ligand-target binding include conformational rigidity and multiple hydrogen bonds between ligand and protein.

Figure 4 illustrates some of the difficulties in using GE in analysis of SAR. The two GE values reported [3] for the Hsp90 inhibitor shown in Figure 4A were derived from published SAR [92] that is summarized in Figure 4B. The $\left(\Delta \mathrm{pK} \mathrm{D}_{\mathrm{D}} / \Delta \mathrm{N}_{\mathrm{nH}}\right)$ value of 0.8 per non-hydrogen atom for $[\mathbf{9} \rightarrow \mathbf{1 2}]$ would place it in the top quartile of the F2L optimizations surveyed in J2018 [75]. Addition of the second hydroxyl group and merging the diethylamino group with a benzene ring each appears to result in an affinity increase of two orders of magnitude. However, it is not possible to determine whether or not the SAR is additive without knowing the affinity for 11. Graphics such as Figure 4A cannot capture the order in which the structural transformations are carried out and, in some cases, even the starting point for the transformation is not clear. For example, it is not possible to determine from Figure 4A whether the isoindoline in $\mathbf{8}$ had been derived from the corresponding dimethylamino, diethylamino or pyrrolidinyl group.

A

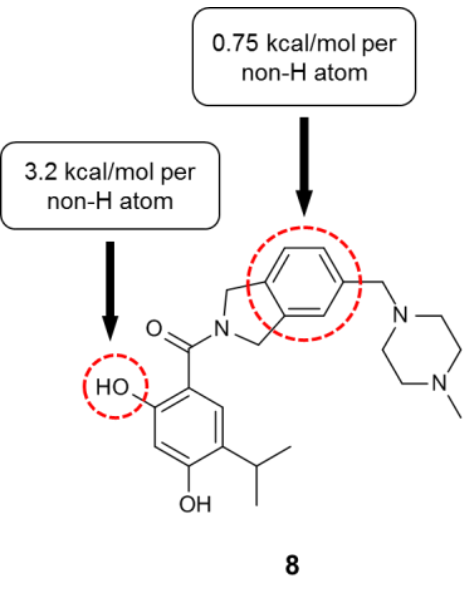

$\mathrm{B}$

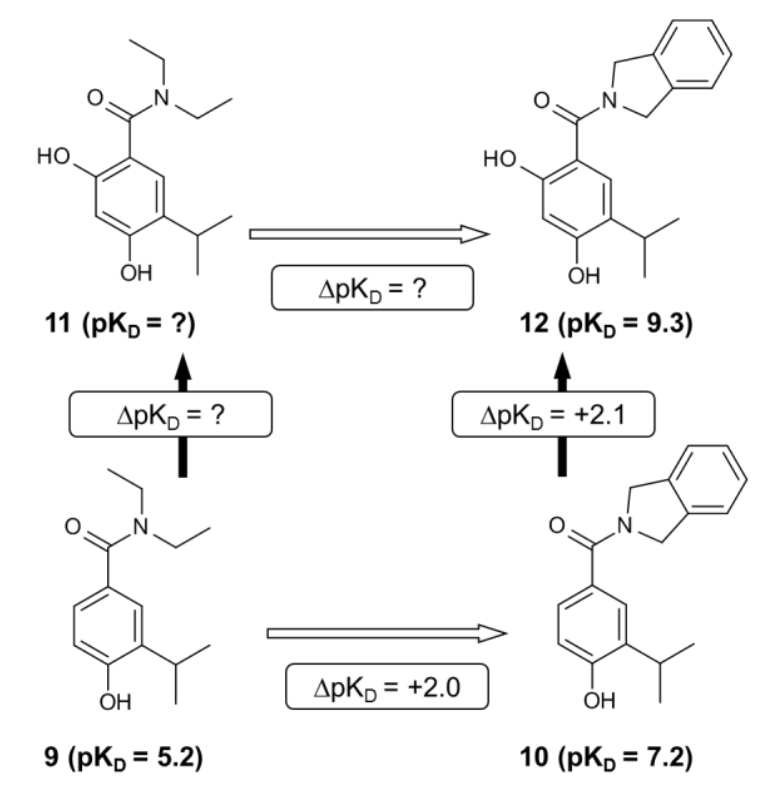

Figure 4. (A) Group efficiency values reported in reference 3 for an HSP90 inhibitor (B) SAR of HSP90 inhibitors from reference 92 


\section{MAXIMAL AFFINITY OF LIGANDS AND FIT QUALITY}

K1999 [32] explored the limits that protein structure may impose on affinity and it is also is widely regarded to have introduced the LE concept. K1999 [32] uses affinity measurements against multiple targets and medicinal chemists should not automatically assume that this study is directly relevant to specific targets on which they may be working. Put another way, if a micromolar activity against a target of interest has been observed for a compound, how useful is it to know that another compound of comparable molecular size has shown picomolar affinity against another target? Sample size is an important consideration in studies of biophysical limits of affinity since the observation of maximal affinity can be regarded as a relatively rare event. How many observations of affinity against how many targets would one need to make for compounds with 20 non-hydrogen atoms in order to have a 95\% chance of observing affinity within $1.4 \mathrm{kcal} / \mathrm{mol}$ of a theoretical affinity limit for compounds of this molecular size?

K1999 [32] analyzes the relationship between $\Delta \Delta \mathrm{G}_{\text {binding }}$ (numerically equivalent to $\Delta \mathrm{G}^{\circ}$ for $\left.\mathrm{C}^{\circ}=1 \mathrm{M}\right)$ and number of non-hydrogen atoms:

"If we ignore simple cations and anions, the data show a sharp improvement in binding free energy until $\approx 15$ heavy atoms per molecule. The $\Delta \Delta G_{\text {binding }}$ binding of the tightest-binding ligands then plateaus at $\approx-15 \mathrm{kcal} / \mathrm{mol}$ (i.e., picomolar dissociation constants). The initial slope is approximately $-1.5 \mathrm{kcal} / \mathrm{mol}$ per atom."

While the response of $\Delta \mathrm{G}^{\circ}$ to $\mathrm{N}_{\mathrm{nH}}(-0.44 \mathrm{kcal} / \mathrm{mol}$ per non-hydrogen atom) shown in Figure 3B is much less steep than the initial response of $\Delta \Delta \mathrm{G}_{\text {binding }}$ to $\mathrm{N}_{\mathrm{nH}}(-1.5 \mathrm{kcal} / \mathrm{mol}$ per nonhydrogen atom) reported by K1999 [32], its linearity appears to be maintained over the entire molecular size range $\left(5 \leq \mathrm{N}_{\mathrm{nH}} \leq 21\right)$ for the data. The findings from $\mathrm{K} 1999$ [32] do not appear to provide insights that would be useful for the interpretation of the results shown in Figure 3B and this reflects the fact that affinity measured against multiple targets was used for the analysis

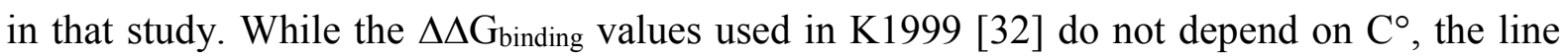
describing the initial response of $\Delta \Delta \mathrm{G}_{\text {binding }}$ to $\mathrm{N}_{\mathrm{nH}}$ was constrained to pass through the point $\left(\mathrm{N}_{\mathrm{nH}}=0 ; \Delta \Delta \mathrm{G}_{\text {binding }}=0\right)$. Shultz noted [93] that imposition of this constraint (equivalent to assuming that $\mathrm{K}_{\mathrm{D}}=1 \mathrm{M}$ for zero molecular size) is likely to have biased the estimate for the steepness of the initial response and others [8] subsequently made similar observations. 
The response of maximal affinity to molecular size shown in K1999 [32] might be anticipated from consideration of molecular complexity [18] and it provides support for the view that additivity [86-91] in SAR decreases with molecular size. Although the choice of intercept in the K1999 [32] has been criticized [8,93], the response of maximal affinity to molecular size was modeled directly in the study. In contrast, Reynolds, Tounge and Bembenek (RTB2008) [94] modeled the response of maximal LE to molecular size. RTB2008 [94] asserted that "ligand efficiency is dependent on ligand size with smaller ligands having greater efficiencies, on average, than larger ligands" and M2014 [58] repeated this assertion. As shown in Figure $1 \mathrm{~B}$, the apparently greater efficiency of smaller ligands can reflect the choice of unit used to express affinity and, therefore, should be not interpreted as having any special significance.

RTB2008 [94] uses fit quality (FQ) to normalize LE with respect to molecular size and claims that "the fit quality score provides a simple method for directly measuring how optimally a ligand binds relative to other ligands of any size" [94]. However, the results presented in Table 1 show that it is not valid to claim that LE measures how optimally a ligand binds, even to a single protein, since rankings of compounds can vary with the concentration unit in which $\mathrm{K}_{\mathrm{D}}$ is expressed. Given that the degree to which a ligand binds optimally has not been shown to be an experimental observable, it would not be valid to make a claim for direct measurement even if perception of efficiency was independent of $\mathrm{C}^{\circ}$. FQ was introduced to address a perceived deficiency of LE and it has been stated [59] that "LE can break down when comparing ligands of disparate size (LLE, FQ and size independent ligand efficiency [SILE] are better)."

The calculation of FQ involves first deriving the LE_Scale function by modelling the maximal LE as a function of $\mathrm{N}_{\mathrm{nH}}$ to provide a reference for scaling LE values [94]. FQ is defined as the ratio of LE to LE_Scale which means that it is simply a ratio of $\Delta \mathrm{G}^{\circ}$ values and therefore dependent on $\mathrm{C}^{\circ}$. This is a separate issue from the dependence of $\mathrm{LE}$ on $\mathrm{C}^{\circ}$ since the comparison between LE and LE_Scale is made using the same value of $\mathrm{N}_{\mathrm{nH}}$. Although it should be possible to address the problems associated with using $\Delta \mathrm{G}^{\circ}$ ratios by using $\Delta \Delta \mathrm{G}$, there remains the issue that affinity values used for the calculation of LE and LE_scale do not generally correspond to the same protein. This means that a low value of FQ could just as plausibly be explained by low TIP of the target as by suboptimal interactions with the target.

The analysis presented in RTB2008 [94] can also be criticized from a general cheminformatic perspective. While the dependence of maximal binding affinity on molecular size may be of interest to drug discovery scientists, there are a number of reasons why this relationship would 
be better modelled directly with $\Delta \mathrm{G}^{\circ}$ (or $\mathrm{pK}$ ) as the dependent variable and $\mathrm{N}_{\mathrm{nH}}$ as the independent variable. First, using affinity as the dependent variable means that there are none of the difficulties caused by the dependence of $\mathrm{LE}$ on $\mathrm{C}^{\circ}$ since a change in $\mathrm{C}^{\circ}$ simply shifts affinity by a constant amount that is independent of molecular size. Second, it is not generally possible to assess quality of fit in a meaningful manner when fitting a quantity (e.g., $\left.p K_{D} / N_{n H}\right)$ that depends explicitly on the independent variable (e.g., $\mathrm{N}_{\mathrm{nH}}$ ). This is because, to some extent, the modelling process involves fitting the independent variable to itself. Third, scaling affinity by molecular size also scales the uncertainty in the affinity by molecular size and this needs to be properly accounted for when performing the regression analysis. Sheridan has debunked the suggestion that LE is inherently more predictable than affinity [95].

\section{ALTERNATIVES TO LIGAND EFFICIENCY FOR NORMALIZATION OF AFFINITY}

Despite the criticisms made of the LE metric and its variants, the view that the best compounds punch above their weight is still valid. While it does not appear possible to define LE objectively in an absolute sense, the H2006 [33] and S2007 [34] studies showed that efficiency can be defined in relative terms. With appropriate data analysis, it may be possible to establish a particular value of $\left(\Delta \mathrm{pK} \mathrm{D}_{\mathrm{D}} / \Delta \mathrm{N}_{\mathrm{nH}}\right)$ as indicative that two compounds bind with equal efficiency.

LE was introduced [1] as a means to normalize affinity with respect to molecular size and this raises the question of whether or not meaningful normalization can be achieved without having to assume a particular value of $\mathrm{C}^{\circ}$. Although $\mathrm{GE}$ does not vary with $\mathrm{C}^{\circ}$, this metric is associated with structural transformations, rather than compounds, and so cannot be used to normalize affinity of compounds. To describe data as normalized would generally imply that some preliminary analysis has been performed on the data. For example, one might subtract the mean molecular weight for the fragments in a screening library from the molecular weight of each fragment. Mean-centering data in this manner makes it possible to determine at a glance whether or not a fragment in the library is larger than average.

Affinity can be normalized with respect to design risk factors such as molecular size in a manner that is analogous to mean-centering by using the trend in the data instead of the mean. This is analogous to the approach that was used in the ACM1984 study [52] and has been outlined in previous studies [8,42]. The response of affinity to molecular size is first modelled so that the trend in the data can be represented by the $\mathrm{pK}_{\mathrm{D}}$ values predicted by the model. 
Affinity is then normalized by subtraction of predicted $\mathrm{pK}_{\mathrm{D}}$ from the experimentally measured value (this difference is conventionally referred to as the residual):

$$
p K_{D}[\text { resd }]=p K_{D}[\operatorname{expt}]-p K_{D}[p r e d]
$$

A large absolute value of a residual can be seen as a type of activity cliff [37,38] and the most interesting SAR is likely to be associated with the most deviant values. A large positive residual could reflect a different type of molecular interaction while a large negative residual might be linked to the absence of a key molecular recognition element. Affinity (or potency) should always be plotted as a function of molecular size during the course of an F2L project and even a weak trend can be used to normalize data. Modelling the data in the initial stages of an F2L project may indicate the likely response of affinity to a further increase in molecular size and the greater sensitivity to structural elaboration of one fragment hit may trump the greater potency of another when setting priorities.

A
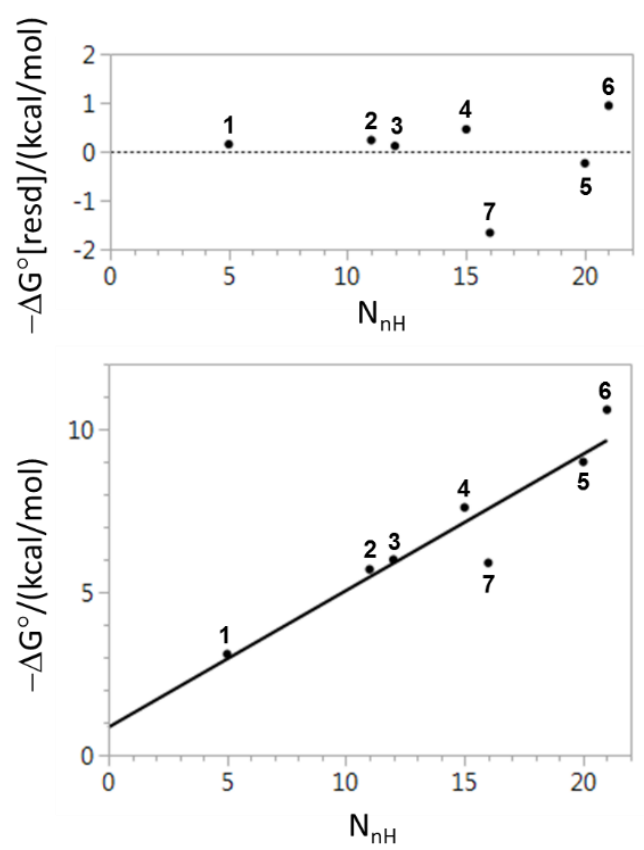

B
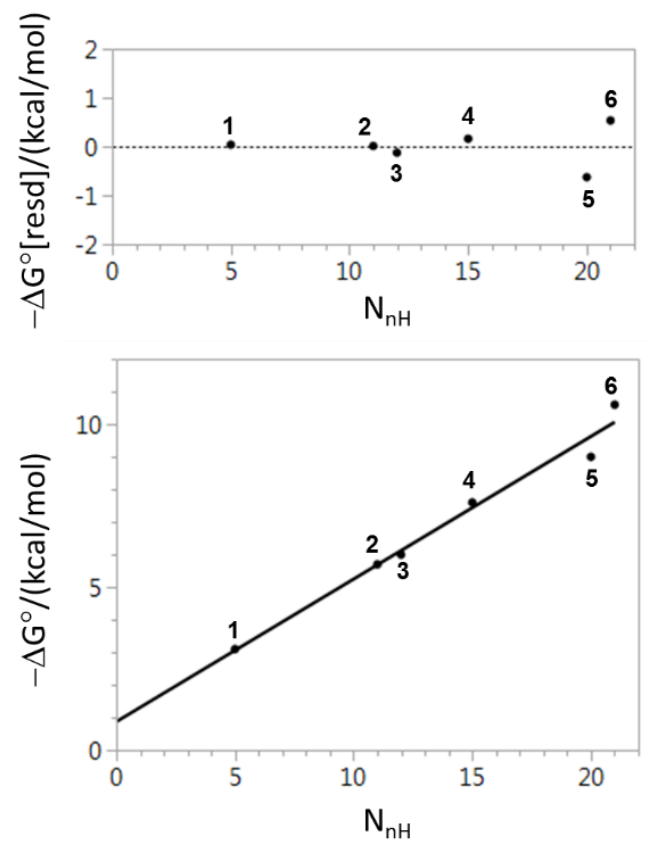

Figure 5. Normalization of data from reference 34 (A) Data set includes 7 (B) Data set excludes 7

This approach to normalization of affinity with respect to molecular size can be illustrated using the data from S2007 [34]. The results of fitting $-\Delta \mathrm{G}^{\circ}$ to $\mathrm{N}_{\mathrm{nH}}$ are shown in Figure 5 and summarized in Table 3. The large negative residual $(-1.7 \mathrm{kcal} / \mathrm{mol})$ for 7 shown in Figure $5 \mathrm{~A}$ highlights the importance of the pyrazole substructure for affinity. One advantage of analyzing 
the data in this manner is that all compounds are treated equivalently in the analysis so there is no need to make a special case of the structural prototype $\mathbf{1}$.

Once it has been established that the pyrazole substructure is important for affinity, the nonpyrazole 7 can be excluded from the dataset to enable affinity to be normalized for the pyrazoles (Figure 5B). The results in Table 3 show a very strong relationship $\left(\mathrm{R}^{2}=0.98 ; \mathrm{RMSE}=0.42\right.$ $\mathrm{kcal} / \mathrm{mol}$ ) between $\Delta \mathrm{G}^{\circ}$ and $\mathrm{N}_{\mathrm{nH}}$ and practically all the variation in $\Delta \mathrm{G}^{\circ}$ for these compounds can be explained by differences in molecular size. The two residuals of greatest magnitude correspond to $5(-0.6 \mathrm{kcal} / \mathrm{mol})$ and $6(+0.5 \mathrm{kcal} / \mathrm{mol})$ and these values reflect the large GE value of $1.6 \mathrm{kcal} / \mathrm{mol}$ per non-hydrogen atom reported for the $[5 \rightarrow \mathbf{6}]$ transformation. A significant portion $(\approx-0.4 \mathrm{kcal} / \mathrm{mol})$ of the residual for 5 can probably be explained by its racemic nature. Had the more active enantiomer of $\mathbf{5}$ been used in the analysis, the GE value for the chloro-substitution might have been $1.2 \mathrm{kcal} / \mathrm{mol}$ per non-hydrogen atom rather than $1.6 \mathrm{kcal} / \mathrm{mol}$ per non-hydrogen atom as reported in S2007. ${ }^{35}$ Both the residual for 6 and the GE value for the $[\mathbf{5} \rightarrow \mathbf{6}]$ transformation highlight the importance of the chloro substituent as a molecular recognition element in this system. Given that the pyrazole ring is present in all structures, it is not possible to draw any inference about the contribution of this molecular recognition element to affinity although the excellent linear fit to the data shown in Figure 5B is consistent with a view that structural elaboration did not compromise the hydrogen bonding between pyrazole and the hinge region of PKB.

Table 3. Results of fitting linear model to data from S2007 study

\begin{tabular}{|l|l|l|l|l|l|l|l|}
\hline & \multicolumn{7}{|c|}{$-\Delta \mathrm{G}^{\circ} /(\mathrm{kcal} / \mathrm{mol})=\mathrm{A}_{0}+\left(\mathrm{A}_{1} \times \mathrm{N}_{\mathrm{nH}}\right)$} \\
\hline Dataset & $\mathrm{N}^{\mathrm{a}}$ & $\mathrm{A}_{0}$ & $\mathrm{SE} \mathrm{A}{ }^{\mathrm{b}}$ & $\mathrm{A}_{1}$ & $\mathrm{SE} \mathrm{A}_{1}{ }^{\mathrm{c}}$ & $\mathrm{RMSE}^{\mathrm{d}}$ & $\mathrm{R}^{2 \mathrm{e}}$ \\
\hline Compounds 1-7 & 7 & 0.85 & 1.00 & 0.42 & 0.07 & 0.89 & 0.89 \\
\hline Compounds 1-6 & 6 & 0.87 & 0.48 & 0.44 & 0.03 & 0.42 & 0.98 \\
\hline
\end{tabular}

\footnotetext{
${ }^{a}$ Number of observations

${ }^{\mathrm{b}}$ Standard error in $\mathrm{A}_{0}$

${ }^{\mathrm{c}}$ Standard error in $\mathrm{A}_{1}$

${ }^{\mathrm{d}}$ Root mean square error

${ }^{\mathrm{e}}$ Coefficient of determination
} 
Analyzing affinity data in this manner effectively partitions MSE for a compound into a term that characterizes the steepness of response of affinity to molecular size for the particular selection of compounds and a residual term that quantifies the extent to which the affinity of a compound beats (or is beaten by) the trend in the data. The residuals are invariant with respect to change in $\mathrm{C}^{\circ}$ so there is no change in perception if affinity is expressed using a different concentration unit. Although residuals cannot be used to define efficiency in an absolute sense, compounds can still be ranked and there is no requirement, as is the case for analysis based on GE $[34,85]$, that the compounds be structurally related. Affinity can be normalized with respect to other risk factors (e.g., lipophilicity) using residuals and other properties (e.g., aqueous solubility) can be normalized in an analogous manner. When using residuals for normalization of affinity, there is no requirement that the model be either linear or univariate. This means that affinity can be normalized with respect to more than one risk factor in a single analysis.

Drug discovery scientists typically need be able to address a range of questions when interrogating project data. For example, it may be useful to focus analysis on the most active compounds in an optimization project. It is important to stress that residuals are not generated in isolation and they result from analysis that, arguably, should be performed anyway. The line fit to a plot of affinity against molecular size is likely to be a better predictor of outcome than a line that has been artificially forced to intercept the affinity axis at a point corresponding to a $\mathrm{K}_{\mathrm{D}}$ value of $1 \mathrm{M}$ [8]. The strength of the trend also provides an indication of how useful normalization of the data is likely to be. For example, the observation of a very weak correlation between affinity and molecular size for hits from a fragment screen suggests that molecular size need not be accounted for when assessing the fragment hits in question. In an optimization project, a relatively weak correlation between affinity and molecular size may point to SAR that is specific to the extent that it cannot be adequately explained by molecular size alone. 


\section{CONCLUSIONS}

LE has been discussed in depth from a physicochemical perspective in this study and the difficulty of interpreting affinity in terms of molecular interactions was highlighted. The nontrivial dependency of LE on the concentration unit in which affinity is expressed means that LE has no physical significance and, strictly, should not even be considered to be a metric. As such, LE is unsuitable for ranking compounds, setting acceptability thresholds for affinity and modeling relationships between affinity and molecular size. While it does not appear to be possible to quantify efficiency of binding objectively for compounds in an absolute manner, efficiency can still be defined in a relative manner by scaling affinity differences by the corresponding molecular size differences.

\section{AUTHOR INFORMATION}

\section{Corresponding Author}

*Email, pwk.pub.2008@gmail.com

\section{ACKNOWLEDGMENT}

I thank Michael Gilson for helpful comments on the manuscript.

\section{ABBREVIATIONS}

$\mathrm{C}^{\circ}$, standard concentration, FBLD, fragment-based lead discovery; FQ, fit quality; F2L, fragment-to-lead; GE, group efficiency; $\mathrm{IC}_{50}$, half maximal inhibitory concentration; $\mathrm{K}_{\mathrm{D}}$, dissociation constant; LE, ligand efficiency; LE_Scale, estimate for maximal ligand efficiency as function of $\mathrm{N}_{\mathrm{nH}}$; LipE, lipophilic efficiency; LLE, ligand lipophilicity efficiency or lipophilic ligand efficiency; $\log \mathrm{D}$, base 10 logarithm of octanol/water distribution coefficient; $\log \mathrm{P}$, base 10 logarithm of octanol/water partition coefficient; $\mathrm{N}_{\mathrm{nH}}$, number of non-hydrogen atoms in a molecular structure; $\mathrm{P}$, octanol/water partition coefficient; $\mathrm{pIC}_{50},-\log _{10}\left(\mathrm{IC}_{50} / \mathrm{M}\right) ; \mathrm{pK}$, $-\log _{10}\left(\mathrm{~K}_{\mathrm{D}} / \mathrm{M}\right) ; \mathrm{pK} \mathrm{D}_{\mathrm{D}}[\mathrm{expt}]$, experimentally measured $\mathrm{pK} \mathrm{D}_{\mathrm{D}} ; \mathrm{p} \mathrm{K}_{\mathrm{D}}[\mathrm{pred}]$, value of $\mathrm{pK} \mathrm{D}_{\mathrm{D}}$ predicted by model; $\mathrm{pK}_{\mathrm{D}}[$ resd], residual $\mathrm{pK} \mathrm{D} ; \mathrm{R}$, gas constant; Ro3, rule of 3; Ro5, rule of 5; $\mathrm{T}$, thermodynamic temperature; TIP, target interaction potential; $\Delta \mathrm{g}^{\circ}$, ligand efficiency calculated from standard free energy of binding; $\Delta \mathrm{G}^{\circ}$, standard free energy of binding; $\Delta \mathrm{N}$, change in number of chemical species; $\eta_{\text {bind, }}$, ligand efficiency calculated from logarithmically expressed $K_{D}$ without energy units. 


\section{REFERENCES}

1. Hopkins AL, Groom CR, Alex A (2004) Ligand efficiency: a useful metric for lead selection. Drug Discov Today 9:430-431. http://doi.org/10.1016/S1359-6446(04)03069-7

2. Abad-Zapatero C, Perisic O, Wass J, Bento PA, Overington J, Al-Lazikani B, Johnson ME (2010) Ligand efficiency indices for an effective mapping of chemico-biological space: the concept of an atlas-like representation. Drug Discov Today 2010, 15, 804-811. http://doi.org/10.1016/j.drudis.2010.08.004

3. Hopkins AL, Keserü GM, Leeson PD, Rees DC, Reynolds CH (2014) The role of ligand efficiency metrics in drug discovery. Nat Rev Drug Discov 13:105-121. http://doi.org/10.1038/nrd4163

4. Meanwell NA (2016) Improving drug design: an update on recent applications of efficiency metrics, strategies for replacing problematic elements, and compounds in nontraditional drug space. Chem Res Toxicol 29:564-616. http://dx.doi.org/10.1021/acs.chemrestox.6b00043

5. Cavalluzzi MM, Mangiatordi GF, Moro A, Nicolotti O, Lentini G (2017) Ligand efficiency metrics in drug discovery: the pros and cons from a practical perspective. Exp Opin Drug Discov 12:1087-1104. http://doi.org/10.1080/17460441.2017.1365056

6. Young RJ, Leeson PD (2018) Mapping the efficiency and physicochemical trajectories of successful optimizations. J Med Chem 61:6421-6467. http://dx.doi.org/10.1021/acs.jmedchem.8b00180

7. Zhou HX, Gilson MK (2009) Theory of free energy and entropy in noncovalent binding. Chem Rev 109:4092-4107. http://doi.org/10.1021/cr800551w

8. Kenny PW, Leitão A, Montanari CA (2014) Ligand efficiency metrics considered harmful. J. Comput Aided Mol Des 28:699-710. http://doi.org/10.1007/s10822-014-9757-8

9. Matta CF, Massa L, Gubskaya AV, Knoll E (2011) Can one take the logarithm or the sine of a dimensioned quantity or a unit? Dimensional analysis involving transcendental functions. J Chem Educ 88:67-70. http://dx.doi.org/10.1021/ed1000476

10. Birch AM, Kenny PW, Simpson I, Whittamore PRO (2009) Matched molecular pair analysis of activity and properties of glycogen phosphorylase inhibitors. Bioorg Med Chem Lett 19:850-853. http://doi.org/10.1016/j.bmcl.2008.12.003

11. Chodera JD, Mobley DL, Shirts MR, Dixon RW, Branson K, Pande VS (2011) Alchemical free energy methods for drug discovery: progress and challenges. Curr Opin Struct Biol 21:150-160. http://doi.org/10.1016/j.sbi.2011.01.011

12. Cournia Z, Allen B, Sherman W (2017) Relative binding free energy calculations in drug discovery: recent advances and practical considerations. J Chem Inf Model 57:2911-2937. http://dx.doi.org/10.1021/acs.jcim.7b00564

13. Nicolaou CA, Brown N (2013) Multi-objective optimization methods in drug design. Drug Discov Today Technol 10:e427-e435. http://doi.org/10.1016/j.ddtec.2013.02.001

14. Kenny PW, Montanari CA (2013) Inflation of correlation in the pursuit of drug-likeness. J ComputAided Mol Des 2013, 27, 1-13. http://doi.org/10.1007/s10822-012-9631-5

15. Mateus A, Matsson P, Artursson P (2013) Rapid measurement of intracellular unbound drug concentrations. Mol Pharm 10:2467-2478. http://dx.doi.org/10.1021/mp4000822

16. Gordon LJ, Allen M, Artursson P, Hann MM, Leavens BJ, Mateus A, Readshaw S, Valko K, Wayne GJ, West A (2016) Direct measurement of intracellular compound concentration by RapidFire mass spectrometry offers insights into cell permeability. J Biomol Screen 21:156-164. http://doi.org/10.1177/1087057115604141

17. Oprea TI, Davis AM, Teague SJ, Leeson PD (2001) Is there a difference between leads and drugs? A historical perspective. J Chem Inf Comput Sci 41:1308-1315. http://dx.doi.org/10.1021/ci010366a 
18. Hann MM, Leach AR, Harper G (2001) Molecular complexity and its impact on the probability of finding leads for drug discovery. J Chem Inf Comp Sci 41:856-864. http://dx.doi.org/10.1021/ci000403i

19. Teague SJ, Davis AM, Leeson PD, Oprea T (1999) The design of leadlike combinatorial libraries. Angew Chem Int Ed Engl 38:3743-3748. http://doi.org/10.1002/(SICI)1521-3773(19991216)38:24<3743::AIDANIE3743>3.0.CO;2-U

20. Lipinski CA, Lombardo F, Dominy BW, Feeney PJ (1997) Experimental and computational approaches to estimate solubility and permeability in drug discovery and development settings. Adv Drug Delivery Rev 23:4-25. http://doi.org/10.1016/S0169-409X(96)00423-1

21. Boehm HJ, Boehringer M, Bur D, Gmuender H, Huber W, Klaus W, Kostrewa D, Kuehne, H, Luebbers T, Meunier-Keller N, Mueller F (2000) Novel inhibitors of DNA gyrase: 3D structure based biased needle screening, hit validation by biophysical methods, and 3D guided optimization. A promising alternative to random screening. J Med Chem 43:2664-2674. http://doi.org/10.1021/jm000017s

22. Blomberg N, Cosgrove DA, Kenny PW, Kolmodin K (2009) Design of compound libraries for fragment screening. J Comput Aided Mol Des 23:513-525. http://doi.org/10.1007/s10822-009-9264-5

23. Nicholls A, McGaughey GB, Sheridan RP, Good AC, Warren G, Mathieu M, Muchmore SW, Brown SP, Grant JA, Haigh JA, Nevins N, Jain AN, Kelley B (2010) Molecular shape and medicinal chemistry: A perspective. J Med Chem 53:3862-3886. http://dx.doi.org/10.1021/jm900818s

24. Richards FM (1977) Areas, volumes, packing, and protein structure. Ann Rev Biophys Bioeng 6:151176. http://dx.doi.org/10.1146/annurev.bb.06.060177.001055

25. Pettit FK, Bowie JU (1999) Protein surface roughness and small molecular binding sites. J Mol Biol 285:1377-1382. http://doi.org/10.1006/jmbi.1998.2411

26. Persch E, Dumele O, Diederich F (2015) Molecular recognition in chemical and biological systems. Angew Chem Int Ed 54:3290-3327. http://doi.org/10.1002/anie.201408487

27. Bissantz C, Kuhn B, Stahl M (2010) A medicinal chemist's guide to molecular interactions. J Med Chem 53:5061-5064. http://doi.org/10.1021/jm100112j

28. Mark AE, van Gunsteren WF (1994) Decomposition of the free energy of a system in terms of specific interactions. Implications for theoretical and experimental studies. J Mol Biol 240:167-176. http://doi.org/10.1006/jmbi.1994.1430

29. van de Waterbeemd H, Smith DA, Beaumont K, Walker DK (2001) Property-based design: optimization of drug absorption and pharmacokinetics. J Med Chem. 44:1313-1333. http://dx.doi.org/10.1021/jm000407e

30. Meanwell NA (2011) Improving drug candidates by design: a focus on physicochemical properties as a means of improving compound disposition and safety. Chem Res Toxicol 24:1420-1456. http://dx.doi.org/10.1021/tx200211v

31. Keserü GM, Erlanson DA, Ferenczy GG, Hann MM, Murray CW, Pickett SD (2016) Design principles for fragment libraries - Maximizing the value of learnings from pharma fragment based drug discovery (FBDD) programs for use in academia. J Med Chem 59:8189-8206. http://dx.doi.org/10.1021/acs.jmedchem.6b00197

32. Kuntz ID, Chen K, Sharp KA, Kollman PA (1999) The maximal affinity of ligands. Proc Natl Acad Sci USA 96:9997-10002. http://doi.org/10.1073/pnas.96.18.9997

33. Hajduk PJ (2006) Fragment-based drug design: how big is too big? J Med Chem 49:6972-6976. http://doi.org/10.1021/jm060511h

34. Saxty G, Woodhead SJ, Berdini V, Davies TG, Verdonk ML, Wyatt PG, Boyle RG, Barford D, Downham R, Garrett MD, Carr RA (2007) Identification of inhibitors of protein kinase B using fragmentbased lead discovery. J Med Chem 50:2293-2296. http://dx.doi.org/10.1021/jm070091b 
35. Hammett LP (1937) The effect of structure upon the reactions of organic compounds. Benzene derivatives. J Am Chem Soc 59:96-103. http://dx.doi.org/10.1021/ja01280a022

36. Hammett LP (1938) Linear free energy relationships in rate and equilibrium phenomena. J Chem Soc Faraday Trans 34:156-165. http://dx.doi.org/10.1039/TF9383400156

37. Maggiora GM (2006) On outliers and activity cliffs - Why QSAR often disappoints. J Chem Inf Model 46:1535-1535. http://doi.org/10.1021/ci060117s

38. Stumpfe D, Bajorath J (2012) Exploring activity cliffs in medicinal chemistry. J Med Chem 55:29322942. http://doi.org/10.1021/jm201706b

39. Gilson MK, Given JA, Bush BL, McCammon JA (1997) The statistical-thermodynamic basis for computation of binding affinities: a critical review. Biophys J 72:1047-1069. http://doi.org/10.1016/S0006-3495(97)78756-3

40. Leeson PD, Springthorpe B (2007) The influence of druglike concepts on decision-making in medicinal chemistry. Nat Rev Drug Discov 6:881-890. http://doi.org/10.1038/nrd2445

41. Ryckmans T, Edwards MP, Horne VA, Correia AM, Owen DR, Thompson LR, Tran I, Tutt MF, Young $\mathrm{T}$ (2009) Rapid assessment of a novel series of selective CB2 antagonists using parallel synthesis protocols: a lipophilic efficiency analysis. Bioorg Med Chem Lett 19:4406-4409. https://doi.org/10.1016/j.bmcl.2009.05.062

42. Borges NM, Kenny PW, Montanari CA, Prokopozyk IM, Ribeiro JF, Rocha JR, Sartori GR (2017) The influence of hydrogen bonding on partition coefficients. J Comput-Aided Mol Des 31:163-181. http://doi.org/10.1007/s10822-016-0002-5

43. Maynard AT, Roberts CD (2016) Quantifying, visualizing, and monitoring lead optimization. J Med Chem 59:4189-4201. http://dx.doi.org/10.1021/acs.jmedchem.5b00948

44. Fiedler K (2011) Voodoo correlations are everywhere - Not only in neuroscience. Perspect Psychol Sci 6:163-171. http://doi.org/10.1177/1745691611400237

45. Hopkins AL, Mason JS, Overington JP (2006) Can we rationally design promiscuous drugs? Curr Opin Struct Biol 16:127-136. http://doi.org/10.1016/j.sbi.2006.01.013

46. Cumming JG, Davis AM, Muresan S, Haeberlein M, Chen H. Chemical predictive modelling to improve compound quality. Nature Rev Drug Discov 12:948-962. http://doi.org/10.1038/nrd4128

47. Oprea TI, Hasselgren C (2017) Predicting target and chemical druggability. In Comprehensive Medicinal Chemistry III; Chackalamannil S, Rotella D, Ward S, Eds; Elsevier pp 429-439. http://dx.doi.org/10.1016/B978-0-12-409547-2.12342-X

48. Leeson PD, Young RJ (2015) Molecular property design: does everyone get it? ACS Med Chem Lett 6:722-725. http://dx.doi.org/10.1021/acsmedchemlett.5b00157

49. Scott DE, Coyne AG, Hudson SA, Abell C (2012) Fragment-based approaches in drug discovery and chemical biology. Biochem 51:4990-5003. http://dx.doi.org/10.1021/bi3005126

50. Jencks WP (1981) On the attribution and additivity of binding energies. Proc Natl Acad Sci USA 78:4046-4050. http://doi.org/10.1073/pnas.78.7.4046

51. Free SM, Wilson JW (1964) A Mathematical contribution to structure-activity studies. J Med Chem 7:395-399. http://doi.org/10.1021/jm00334a001

52. Andrews PR, Craik DJ, Martin JL (1984) Functional group contributions to drug-receptor interactions. J Med Chem 27:1648-1657. http://dx.doi.org/10.1021/jm00378a021

53. Reynolds $\mathrm{CH}$, Reynolds RC (2017) Group additivity in ligand binding affinity: an alternative approach to ligand efficiency. J Chem Inf Model 57:3086-3093. http://dx.doi.org/10.1021/acs.jcim.7b00381 
54. Ladbury JE (2007) Enthalpic efficiency and the role of thermodynamic data in drug development: possibility or a pipeline dream. Eur Pharm Rev 12:59-62.

http://www.europeanpharmaceuticalreview.com/article/1835/enthalpic-efficiency-and-the-role-ofthermodynamic-data-in-drug-development-possibility-or-a-pipeline-dream/

55. Bogan AA, Thorn KS (1998) Anatomy of hot spots in protein interfaces. J Mol Biol 280:1-9. http://doi.org/10.1006/jmbi.1998.1843

56. Edfeldt FNB, Folmer RHA, Breeze AL (2011) Fragment screening to predict druggability (ligandability) and lead discovery success. Drug Discov Today 16:284-287. http://doi.org/10.1016/j.drudis.2011.02.002

57. Krimmer SG, Cramer J, Schiebel J, Heine A, Klebe G (2017) How nothing boosts affinity: hydrophobic ligand binding to the virtually vacated $\mathrm{S}_{1}{ }^{\prime}$ pocket of thermolysin. J Am Chem Soc 139:10419-10431. http://dx.doi.org/10.1021/jacs.7b05028

58. Murray CW, Erlanson DA, Hopkins AL, Keserü GM, Leeson PD, Rees DC, Reynolds CH, Richmond NJ (2014) Validity of ligand efficiency metrics. ACS Med Chem Lett 5:616-618. http://doi.org/10.1021/ml500146d

59. Reynolds $\mathrm{CH}$ (2015) Ligand efficiency metrics: why all the fuss? Future Med Chem 7:1363-1365. http://doi.org/10.4155/fmc. 15.70

60. May PC, Dean RA, Lowe SL, Martenyi F, Sheehan SM, Boggs LN, Monk SA, Mathes BM, Mergott DJ, Watson BM, Stout SL, Timm DE, LaBell ES, Gonzales CR, Nakano M, Jhee SS, Yen M, Ereshefsky L, Lindstrom TD, Calligaro DO, Cocke PJ, Hall DG, Friedrich S, Citron M, Audia JE (2011) Robust central reduction of Amyloid- $\beta$ in humans with an orally available, non-peptidic $\beta$-secretase inhibitor. J Neurosci 31:16507-16516. http://doi.org/10.1523/JNEUROSCI.3647-11.2011

61. Czaplewski LG, Collins I, Boyd EA, Brown D, East SP, Gardiner M, Fletcher R, Haydon DJ, Henstock V, Ingram P, Jones C, Noula C, Kennison L, Rockley C, Rose V, Thomaides-Brears HB, Ure R, Whittaker M, Stokes NR (2009) Antibacterial alkoxybenzamide inhibitors of the essential bacterial cell division protein FtsZ. Bioorg Med Chem Lett 19:524-527. http://doi.org/10.1016/j.bmc1.2008.11.021

62. Doak BC, Zheng J, Dobritzsch D, Kihlberg J (2016) How beyond rule of 5 drugs and clinical candidates bind to their targets. J Med Chem 59:2312-2327. http://dx.doi.org/10.1021/acs.jmedchem.5b01286

63. Verlinde CLJ, Rudenko G, Hol WG (1992) In search of new lead compounds for trypanosomiasis drug design: A protein structure-based linked-fragment approach. J. Comput-Aided Mol Des 6:131-147. https://doi.org/10.1007/BF00129424

64. Carr RA, Congreve M, Murray CW, Rees DC (2005) Fragment based lead discovery: leads by design. Drug Discov Today 10:987-992. http://doi.org/10.1016/S1359-6446(05)03511-7

65. Albert JS, Blomberg N, Breeze AL, Brown AJ, Burrows JN, Edwards PD, Folmer RH, Geschwindner S, Griffen EJ, Kenny PW, Nowak T, Olsson LL, Sanganee H, Shapiro AB (2007) An integrated approach to fragment-based lead generation: philosophy, strategy and case studies from AstraZeneca's drug discovery programmes. Curr Top Med Chem 7:1600-1629. http://doi.org/10.2174/156802607782341091

66. Hubbard RE, Murray JB (2011) Experiences in fragment-based lead discovery. Methods Enzymol 493:509-531. https://doi.org/10.1016/B978-0-12-381274-2.00020-0

67. Davis BJ, Roughley SD (2017) Fragment-based lead discovery. Ann Rep Med Chem 50:371-439. http://doi.org/10.1016/bs.armc.2017.07.002

68. Lamoree B, Hubbard RE (2017) Current perspectives in fragment-based lead discovery (FBLD). Essays Biochem 61:453-464. http://dx.doi.org/10.1042/EBC20170028

69. Miranker A, Karplus M (1991) Functionality maps of binding sites: a multiple copy simultaneous search method. Proteins 11:29-34. http://doi.org/10.1002/prot.340110104

70. Böhm H-J (1992) The computer program LUDI: a new method for the de novo design of enzyme inhibitors. J Comput-Aided Mol Des 6:61-78. http://doi.org/10.1007/BF00124387 
71. Allen KN, Bellamacina CR, Ding X, Jeffery CJ, Mattos C, Petsko GA, Ringe D (1996) An experimental approach to mapping the binding surfaces of crystalline proteins. J Phys Chem 100:2605-2611. http://doi.org/10.1021/jp952516o

72. Shuker SB, Hajduk PJ, Meadows RP, Fesik SW (1996) Discovering high-affinity ligands for proteins: SAR by NMR. Science 274:1531-1534. http://doi.org/10.1126/science.274.5292.1531

73. McCoy MA, Wyss DF (2002) Spatial localization of ligand binding sites from electron current density surfaces calculated from NMR chemical shift perturbations. J Am Chem Soc 124:11758-11763. http://dx.doi.org/10.1021/ja026166c

74. Erlanson DA, Fesik SW, Hubbard RE, Jahnke W, Jhoti H (2016) Twenty years on: the impact of fragments on drug discovery. Nat Rev Drug Discov 15:605-619. http://dx.doi.org/10.1038/nrd.2016.109

75. Johnson CN, Erlanson DA, Jahnke W, Mortenson PN, Rees DC (2018) Fragment-to-lead medicinal chemistry publications in 2016. J Med Chem 61:1774-1784.

http://dx.doi.org/10.1021/acs.jmedchem.7b01298

76. Mannhold R, Poda GI, Ostermann C, Tetko IV (2009) Calculation of molecular lipophilicity: State-ofthe-art and comparison of log P methods on more than 96000 compounds. J Pharm Sci 98:861-893. http://doi.org/10.1002/jps.21494

77. Congreve M, Carr R, Murray C, Jhoti H (2003) A "rule of three" for fragment-based lead discovery? Drug Discov Today 8:876-877. http://doi.org/10.1016/S1359-6446(03)02831-9

78. Köster H, Craan T, Brass S, Herhaus C, Zentgraf M, Neumann L, Heine A, Klebe GA (2011) Small nonrule of 3 compatible fragment library provides high hit rate of endothiapepsin crystal structures with various fragment chemotypes, J Med Chem 54:7784-7796. http://dx.doi.org/10.1021/jm200642w

79. Meanwell NA (2011) Synopsis of some recent tactical application of bioisosteres in drug design. J Med Chem 54:2529-2591. http://doi.org/10.1021/jm1013693

80. Herr RJ (2002) 5-Substituted-1H-tetrazoles as carboxylic acid isosteres: medicinal chemistry and synthetic methods. Bioorg Med Chem 10:3379-3393. http://doi.org/10.1016/S0968-0896(02)00239-0

81. Ammazzalorso A, De Filippis B, Giampietro L, Amoroso R (2017) N-acylsulfonamides: synthetic routes and biological potential in medicinal chemistry. Chem Biol Drug Des 90:1094-1105. http://doi.org/10.1111/cbdd.13043

82. Geschwindner S, Olsson LL, Albert JS, Deinum J, Edwards PD, Beer T, Folmer RH (2007) Discovery of a novel warhead against beta-secretase through fragment-based lead generation. J Med Chem 50:59035911. http://doi.org/10.1021/jm070825k

83. Edwards P D, Albert J S, Sylvester M, Aharony D, Andisik D, Callaghan O, Campbell J B, Carr R A, Chessari G, Congreve M, Frederickson M, Folmer R H, Geschwindner S, Koether G, Kolmodin K, Krumrine J, Mauger R C, Murray C W, Olsson L L, Patel S, Spear N, Tian G (2007) Application of fragment-based lead generation to the discovery of novel, cyclic amidine beta-secretase Inhibitors with nanomolar potency, cellular activity, and high ligand efficiency. J Med Chem 50:5912-5925. https://doi.org/10.1021/jm070829p

84. Silva DG, Ribeiro JFR, De Vita D; Cianni L, Franco CH, Freitas-Junior LH, Moraes CB, Rocha JR, Burtoloso ACB, Kenny PW, Leitão A, Montanari CA (2017) A comparative study of warheads for design of cysteine protease inhibitors. Bioorg Med Chem Lett 27:5031-5035. https://doi.org/10.1016/j.bmcl.2017.10.002

85. Verdonk ML, Rees DC (2008) Group efficiency: a guideline for hits-to-leads chemistry. ChemMedChem 3:1179-1180. https://doi.org/10.1002/cmdc.200800132

86. Bridges AJ, Zhou H, Cody DR, Rewcastle GW, McMichael A, Showalter HD, Fry DW, Kraker AJ, Denny WA (1996) Tyrosine kinase inhibitors. 8. An unusually steep structure-activity relationship for analogues of 4-(3-bromoanilino)-6,7- dimethoxyquinazoline (PD 153035), a potent inhibitor of the epidermal growth factor receptor. J Med Chem 39:267-276. http://dx.doi.org/10.1021/jm9503613 
87. Dill KA (1997) Additivity principles in biochemistry. J Biol Chem 272:701-704. http://dx.doi.org/10.1074/jbc.272.2.701

88. Baum B, Muley L, Smolinski M, Heine A, Hangauer D, Klebe G (2010) Non-additivity of functional group contributions in protein-ligand binding: a comprehensive study by crystallography and isothermal titration calorimetry. J Mol Biol 397:1042-1054. http://doi.org/10.1016/j.jmb.2010.02.007

89. Biela A, Betz M, Heine A, Klebe G (2012) Water makes the difference: rearrangement of water solvation layer triggers non-additivity of functional group contributions in protein-ligand binding. ChemMedChem 7:1423-1434. http://doi.org/10.1002/cmdc.201200206

90. Kramer C, Fuchs JE, Liedl KR (2015) Strong nonadditivity as a key structure-activity relationship feature: distinguishing structural changes from assay artifacts. J Chem Inf Model 55:483-494. http://dx.doi.org/10.1021/acs.jcim.5b00018

91. Calabrò G, Woods CJ, Powlesland F, Mey ASJS, Mulholland AJ, Michel J (2016) Elucidation of nonadditive effects in protein-ligand binding energies: thrombin as a case study. J Phys Chem B 120:5340-5350. http://dx.doi.org/10.1021/acs.jpcb.6b03296

92. Murray CW, Carr MG, Callaghan O, Chessari G, Congreve M, Cowan S, Coyle JE, Downham R, Figueroa E, Frederickson M, Graham B, McMenamin R, O’Brien MA, Patel S, Phillips TR, Williams G, Woodhead AJ, Woolford A (2010) J. Fragment-based drug discovery applied to Hsp90. Discovery of two lead series with high ligand efficiency. J Med Chem 53:5942-5955. http://dx.doi.org/10.1021/jm100059d

93. Shultz MD (2013) Setting expectations in molecular optimizations: strengths and limitations of commonly used composite parameters. Bioorg Med Chem Lett 23:5980-5991. https://doi.org/10.1016/j.bmcl.2013.08.029

94. Reynolds CH, Tounge BA, Bembenek SD (2008) Ligand binding efficiency: trends, physical basis, and implications. J Med Chem 51:2432-2438. https://doi.org/10.1021/jm701255b

95. Sheridan RP (2016) Debunking the idea that ligand efficiency indices are superior to pIC50 as QSAR activities. J Chem Inf Model 56:2253-2262. http://dx.doi.org/10.1021/acs.jcim.6b00431 